\title{
Initial Validation of Robotic Operations for In-Space Assembly of a Large Solar Electric Propulsion Transport Vehicle
}

\author{
Erik E. Komendera * and John T. Dorsey ${ }^{\dagger}$ \\ NASA Langley Research Center, Hampton, VA 23681, USA
}

\begin{abstract}
Developing a capability for the assembly of large space structures has the potential to increase the capabilities and performance of future space missions and spacecraft while reducing their cost. One such application is a megawatt-class solar electric propulsion (SEP) tug, representing a critical transportation ability for the NASA lunar, Mars, and solar system exploration missions. A series of robotic assembly experiments were recently completed at Langley Research Center (LaRC) that demonstrate most of the assembly steps for the SEP tug concept. The assembly experiments used a core set of robotic capabilities: long-reach manipulation and dexterous manipulation. This paper describes cross-cutting capabilities and technologies for in-space assembly (ISA), applies the ISA approach to a SEP tug, describes the design and development of two assembly demonstration concepts, and summarizes results of two sets of assembly experiments that validate the SEP tug assembly steps.
\end{abstract}

\section{Nomenclature}

A Assembly steps

$A_{i} \quad$ Assembly step $i$

ATLAST Advanced Technology Large Aperture Space Telescope

DOD Department of Defense

DOF Degrees of Freedom

EBW Electron Beam Welding

EMC Evolvable Mars Campaign

HMA Hot Melt Adhesive

IPJR Intelligent Precision Jigging Robot

ISA In-Space Assembly

ISS International Space Station

LaRC Langley Research Center

LBT Left Backbone Truss

LHT Left-Hand TALISMAN

LIDAR Light Detection and Ranging

LSMS Lightweight Surface Manipulation System

$R_{t} \quad$ State of the robots at time $t$

RBT Right Backbone Truss

RHT Right-Hand TALISMAN

$\rho \quad$ Number of robots in workspace

$S_{t} \quad$ State of the structure at time $t$

SA Solar array

SALSSA Space Assembly of Large Structural System Architectures SEP Solar Electric Propulsion

*Research Aerospace Engineer, Structural Mechanics and Concepts Branch, Mail Stop 190, Member AIAA.

†Senior Research Engineer, Structural Mechanics and Concepts Branch, Mail Stop 190, Associate Fellow AIAA. 


$\begin{array}{ll}\sigma & \text { Number of structural elements in workspace } \\ \Sigma_{t} & \text { Combined state estimate covariance at time } t \\ t & \text { Time } \\ \text { TALISMAN Tendon-Actuated Lightweight In-Space MANipulator } \\ U_{t} & \text { Commands given to all robots at time } t \\ X_{t} & \text { Combined state of structure and robots at time } t \\ \bar{X}_{t} & \text { Combined state estimate mean at time } t \\ Z_{t} & \text { All measurements taken at time } t\end{array}$

\section{Introduction}

The majority of space platforms, except for the International Space Station (ISS), are transported to orbit as an integrated unit using a single launch. Using a single launch approach severely constrains the mass and size of the spacecraft due to the mass and volume constraints of the chosen launch vehicle and the loads imposed by the launch environment. Developing a robust approach to space assembly of large structural system architectures (SALSSA) has the potential to drastically increase the capabilities and performance of future space missions and spacecraft while significantly reducing their cost. Currently, NASA Architecture Studies and Space Science Decadal Surveys have identified new missions that would benefit from SALSSA capabilities. However, the technologies that support SALSSA are interspersed throughout fourteen NASA Technology Roadmaps. Thus, a major impediment to developing SALSSA technologies has been the lack of an integrated and comprehensive compilation of the necessary information to enable strategic development of cross-cutting SALSSA technologies. Recently, a study was completed ${ }^{1}$ that had the goal of developing an integrated approach; a cohesive roadmap and plan for SALSSA technology development.

The first part of the study reviewed current NASA Mission Architecture Studies, ${ }^{2,3}$ Space Science Decadal Surveys ${ }^{4},{ }^{5}$ and Technology Area Roadmaps. ${ }^{6}$ Although modular systems, on-orbit assembly, and in-space servicing are discussed at various levels in these separate documents, there was no single, comprehensive compilation of these capabilities, or the technologies required to support them as represented by the SALSSA approach. The SALSSA roadmap was created by extracting applicable information and compiling it into a comprehensive roadmap that specifically addresses autonomous robotic in-space assembly (ISA). The SALSSA roadmap proposes a plan for phasing the SALSSA approach into future missions, such as those described in. ${ }^{7}$ From that phasing, representative missions and definitions of their systems were selected, and improvements to mission function that were enabled by the SALSSA approach were identified. A fundamental set of the SALSSA capability areas, that are versatile across all applicable missions and architectures, were ultimately defined.

The second part of the study selected three focus applications to represent desired NASA mission capabilities that can best be achieved by incorporating the SALSSA approach: 1) a megawatt class solar electric propulsion (SEP) tug, ${ }^{8}$ 2) a nominally 20-meter diameter (main aperture) next generation space telescope, such as the Advanced Technology Large Aperture Space Telescope (ATLAST), ${ }^{9}$ and, 3) repair, replacement and repurposing of major systems modules for the Evolvable Mars Campaign (EMC) spacecraft systems. ${ }^{10}$ For each focus application, a notional large structural system architecture was defined, concepts were developed for discretizing the system into modules that could be orbited using existing commercial launch vehicles, and a concept of operations was developed for robotically assembling the systems in space. From this information, cross-cutting technical capabilities were identified, that would leverage robotic space assembly to field the three focus mission systems, and a significant number of other NASA, commercial and Department of Defense (DOD) missions. Finally, from the set of technical capabilities, examples of specific technologies that enable those capabilities were identified.

The megawatt-class SEP tug represents a critical transportation capability for the NASA lunar, Mars and solar system exploration missions, as evidenced by its inclusion in most of the architecture studies. This application was therefore chosen here as a focus to begin advancing the technology necessary to implement robotic in-space assembly. An approach of developing more detailed concepts of operation for assembling the tug robotically, and developing the necessary robotic and assembly systems is followed. A series of robotic assembly experiments were recently completed at Langley Research Center (LaRC) that demonstrate most of the assembly steps for the SEP tug concept. The assembly experiments used a core set of robotic capabilities: long-reach manipulation, using either the Lightweight Surface Manipulation System (LSMS) ${ }^{11,12}$ or the 
Tendon-Actuated Lightweight In-Space MANipulator (TALISMAN) ${ }^{13-15}$ robots, and dexterous manipulation and jigging using the Intelligent Precision Jigging Robots (IPJR). ${ }^{16}$

The objectives of this paper are to: 1) describe cross-cutting capabilities and technologies for ISA, 2) apply the ISA approach to a SEP tug, including a description of an assembly sequence, 3) describe the design and development of two assembly demonstration concepts, including the robotics hardware and controls capabilities, and, 4) summarize results of two sets of assembly experiments that were performed and which validate the SEP tug assembly steps.

\section{Cross-Cutting Capabilities and Technologies Enabling ISA}

Based on the challenges and implementation/assembly concepts described for the three focus applications in Reference 1, a set of essential cross-cutting capabilities were derived as listed in Table 1. An added benefit of these ISA capabilities is that they are versatile, not only enabling assembly, but also enabling repair, maintenance and refurbishment of space systems, as well as re-purposing spacecraft modules for new missions.

Taking the cross-cutting capabilities listed in the left column of Table 1, together with the more detailed assembly approaches outlined for the three focus applications1, a set of associated technologies that enable ISA were developed and are listed in the right column. Shown in Table 1, many technologies are needed to enable efficient in-space robotic servicing, repair, assembly, and construction operations. Additionally, the lightweight long-reach manipulators need to be dexterous, the modular interfaces need appropriate strength, stiffness, thermal stability, and reversibility. The assembly infrastructure should include, fixtures and robotic jigging for precision assembly, and robotic operations and motion planning algorithms. These technologies in aggregate should be able to assemble requisite structures with a wide variety of sizes and geometries, while proving reduce costs by using robotic infrastructure that is versatile and reusable, and; reduce spacecraft mass by using simple structural elements with efficient load paths. These technologies should also enable versatile spacecraft repair and servicing operations, and support other missions, such as orbital debris removal and asteroid handling and capture.

The design of any infrastructure needed to support ISA operations should occur concurrently with the space mission vehicle design to allow for optimized vehicles and systems. For example, designing capability into the infrastructure to perform precision alignment and controlled mating, docking, or assembly can dramatically reduce requirements in the vehicle hardware for making permanent connections. The infrastructure would also be able to perform the same functions in reverse, allowing for controlled disassembly. This would allow for repair, refurbishment, and reconfiguration of systems into a new vehicle or platform. Placing required capabilities in the infrastructure, can dramatically reduce the cost of each mission. Since much of the infrastructure and devices can perform functions that are applicable to operations on-orbit as well as on planetary surfaces, commonality in design (taking into account various gravity levels), development, fabrication and testing is likely to be realized, leading to built-in multi-mission capability.

\section{Application of ISA Approach to SEP Tug}

An ISA approach was applied in this study to develop a SEP tug while advancing robotic ISA technologies. A notional ISA-based architecture was defined, concepts were developed for discretizing the system into modules that can be orbited by existing launch vehicles, and a sequence was developed for robotically assembling the modules in space.

\section{III.A. Challenges for Single Launch System}

The SEP tug consists of the spacecraft bus and two large solar array (SA) wings (Figure 1). Each solar array wings would supply from $250 \mathrm{~kW}$ to $500 \mathrm{~kW}$ of power to the ion engines. There are significant challenges and limitations to achieving the large surface area of SAs required when restricted to a single deployable system: the arrays must be designed with sufficient structural stiffness to meet a spacecraft fundamental frequency requirement of 0.1 hertz, and meet a strength requirement that can sustain a $0.1 \mathrm{~g}$ acceleration during boost using a chemical stage ${ }^{17}$. 
Table 1. Technologies that enable SALSSA.

\begin{tabular}{|c|c|}
\hline Technical Capability & Enabling Technology Examples \\
\hline Modularity & $\begin{array}{l}\text { - Truss structural concepts } \\
\text { - Robotically deployable concepts } \\
\text { - Simple structural joints } \\
\text { - Modular interfaces (robotically compatible) } \\
\text { - Reversible joining } \\
\text { - Mechanical (high strength, high stiffness, high thermal stability) } \\
\text { - joints } \\
\text { - Rlectrical/data connections } \\
\text { - Wobotically compatible mechanical systems } \\
\text { - Bonding }\end{array}$ \\
\hline Autonomous Operations & $\begin{array}{l}\text { - High precision sensing } \\
\text { - Error detection and correction } \\
\text { - Integration with operations planning } \\
\text { - Optimal action planning algorithms } \\
\text { - Supervised autonomy } \\
\text { - Path planning }\end{array}$ \\
\hline Manipulation Systems & $\begin{array}{l}\text { - Long-reach manipulation: TALISMAN, LSMS } \\
\text { - High-stiffness durable tendons } \\
\text { - IPJRs } \\
\text { - Precision adjustment: } 6 \text { degrees of freedom (DOF) } \\
\text { - Sensors } \\
\text { - High precision actuators }\end{array}$ \\
\hline $\begin{array}{l}\text { Metrology and Assembly } \\
\text { Operations Planning }\end{array}$ & $\begin{array}{l}\text { - Global sensors and targets } \\
\text { - Communications } \\
\text { - Verification (as-built) software sequence planning } \\
\text { - Robotic asset scheduling } \\
\text { - Inspection and verification methods }\end{array}$ \\
\hline On-Site Infrastructure & $\begin{array}{l}\text { - Spacecraft rendezvous support systems } \\
\text { - Spacecraft berthing support hardware } \\
\text { - Module staging/stowage support hardware }\end{array}$ \\
\hline
\end{tabular}

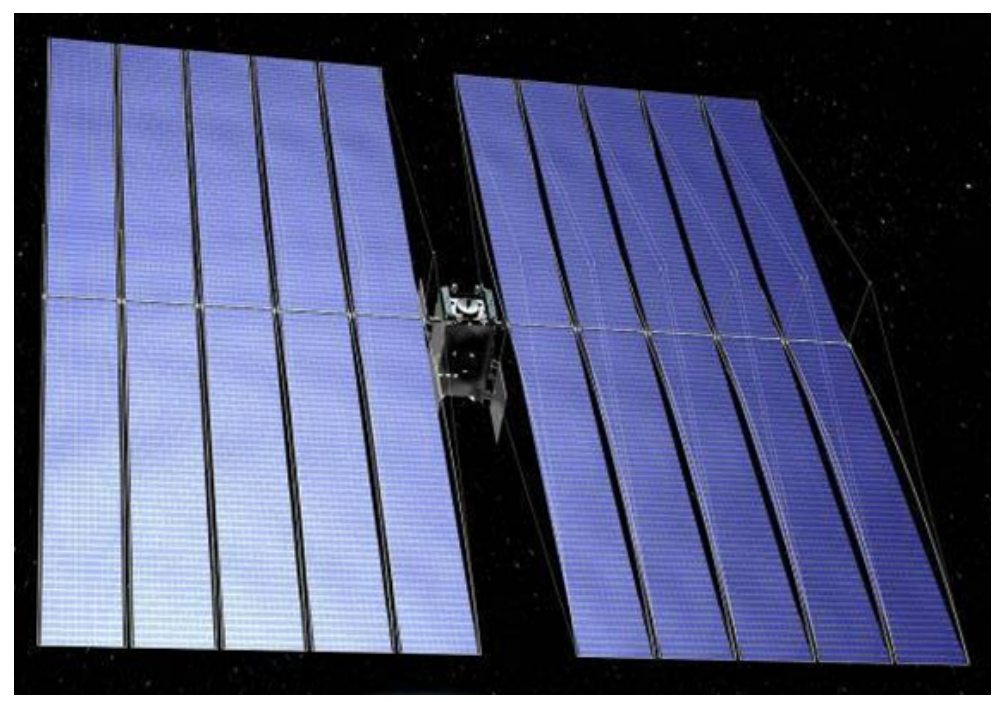

Figure 1. Example of SEP Tug.

\section{III.B. ISA Concept for SEP Tug}

The SEP tug concept being considered would have two solar array wings which consist of a backbone 
truss, onto which current state-of-the-art solar array modules (each $20 \mathrm{~kW}$ to $30 \mathrm{~kW}$ ) are attached. The backbone truss is sized so that the solar array wings meet the spacecraft stiffness and strength requirements. ${ }^{17}$

The complete SEP tug could be subdivided into the following modules: spacecraft bus, two deployable backbone trusses, and 20 deployable solar array wing modules (Figure 1). Multiple launches would be used to place the modules into orbit and locate them at the assembly site. The total number of launches required would depend on the mass and stowed volume of each module, and how the modules could be packaged within the payload mass and volume allocation of a specific launch vehicle. Given a choice of commercial launch vehicles, minimizing total launch cost (regardless of the number of launches required) would be one way to optimize the mission. Allowing some (or all) modules to be launched as secondary payloads, or ride share, could reduce the cost even further.

The on-orbit infrastructure required to assemble the SEP tug would include technologies listed in Table 1, such as: long reach manipulators (TALISMAN), dexterous robots (IPJRs) and specialized tools and processes for joining such as electron beam welding (EBW). In the assembly scenario described here, it is assumed that the backbone truss is a foldable/deployable square (4-longeron) truss that has simple hinge joints and telescoping members in the diagonals. An EBW tool would be used to weld the joints and achieve structural integrity. If no infrastructure existed yet on orbit, options would include attaching the TALISMAN, IPJRs, and EBW (and other) tools to the spacecraft bus and using the bus as the assembly site. One alternative would be to launch a dedicated ISA spacecraft that includes the entire infrastructure and use that as an aggregation site. As ISA becomes more routine, a dedicated ISA platform would become essential for providing services to many customers on a scheduled basis. The IPJR and two TALISMANs in the truss deployment configuration in Figure 2.

Assuming all modules have been launched and aggregated at an ISA site, the assembly might proceed as described below, in accordance with the steps listed in Table 2. Modular connectors (that can complete mechanical, electrical, data and fluid connections) are currently being developed and their existence is assumed here. A long-reach manipulator would deploy a pair of truss bays sequentially, IPJRs would set the geometry of the truss bays, and the joints would be welded or bonded to achieve structural integrity. This concept eliminates all of the deployment motors, mechanisms, and latches associated with conventional deployable trusses; reducing mass and complexity. In this sequence, the entire backbone truss is deployed and rigidized before SA installation begins. A modular connector is pre-integrated at evenly spaced locations on the truss where the SA modules can be attached. A long-reach manipulator with an IPJR tool would position a SA module near the truss interface; IPJR would grapple the modular connector, locate and orient the SA module perpendicular to, and in the center of the truss face complete the connection. The SA modules can be removed for replacement or upgrade at a later date because the modular connector is reversible. The half of the modular connector that is pre-attached to the truss is pre-integrated with the central electrical/data wiring harness that runs down the interior of the backbone truss. Additional SA modules can be attached to each of the wing backbone trusses similarly in a repetitive process to complete each SA wing. Two TALISMANs are assumed in the assembly sequence; one deploys truss sections and holds them in place while the second engages and positions tools such as the IPJR and EBW.

The steps listed in Table 2 are just one example of how the SEP tug might be assembled, with the possibility of adjusting the steps in the sequence depending on the details of the individual module and tool designs. As one alternative, the SA modules could be attached to the deployed sections of a truss as soon as a SA connector became available.

\section{Assembly Operations Concept: Demonstration and Validation}

Two sets of automated assembly ground tests were performed at LaRC to demonstrate many of the operational steps listed in Table 2 that are required to assemble a large SEP tug in space. The two demonstrations were performed in two different laboratories and took advantage of unique features of a particular facility, or used that facility to overcome limitations to the testing. In addition, a unique set of robotic capabilities and assembly support hardware were used for the tests in each facility. In this section, the

robotic systems and their capabilities, the robotic control algorithms development and application, and the assembly demonstrations will be described for each of the two automated assembly tests. 


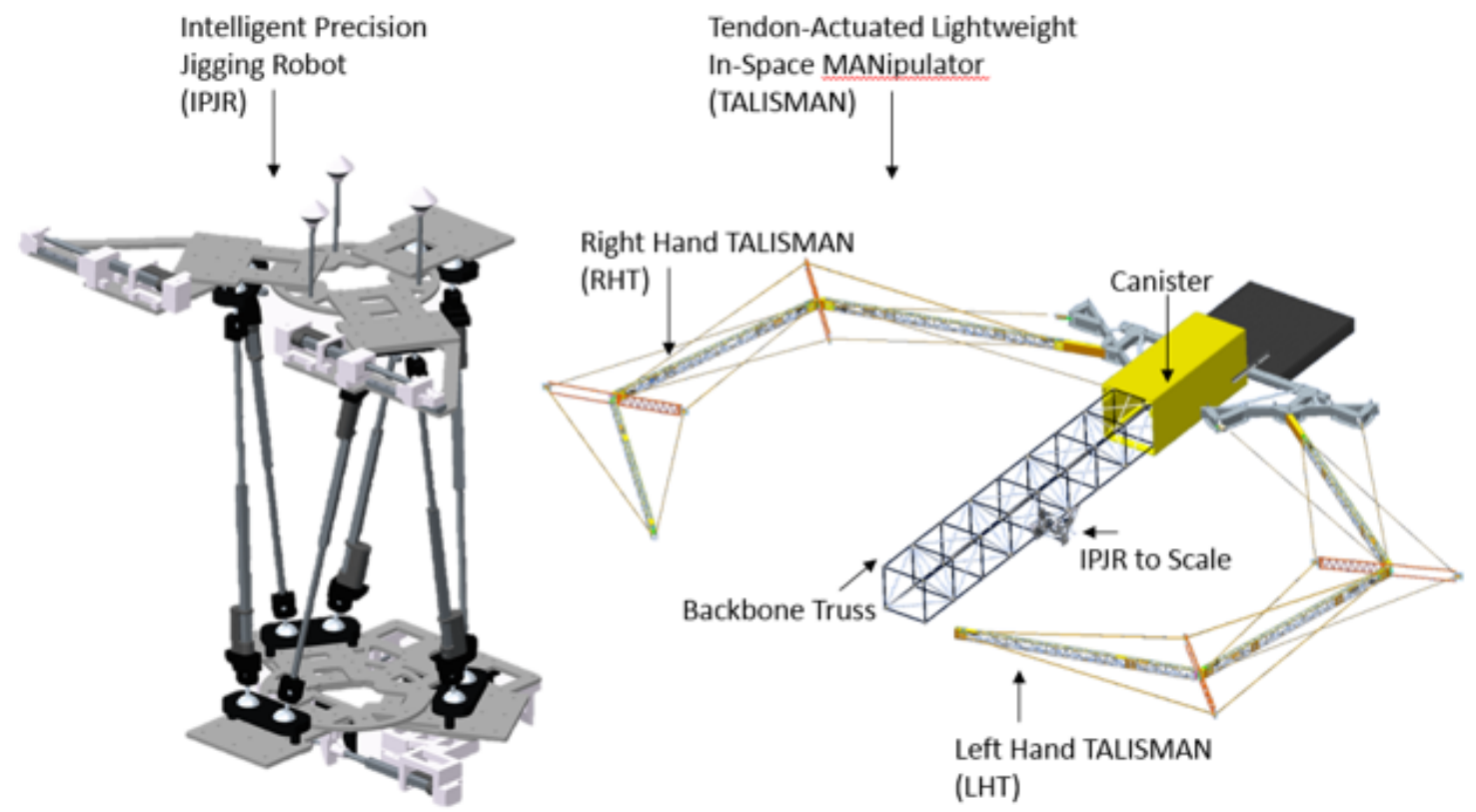

Figure 2. Views of the IPJR and TALISMAN, with test articles shown.

\section{IV.A. Descriptions of Robotic System Capabilities}

\section{IV.A.1. TALISMAN}

The TALISMAN uses a new and innovative robotic architecture that incorporates a combination of lightweight truss links, a novel hinge joint, tendon-articulation and passive tension stiffening to achieve revolutionary performance in a long-reach space manipulator. The major components of the first-generation TALISMAN are listed in Figure 3.

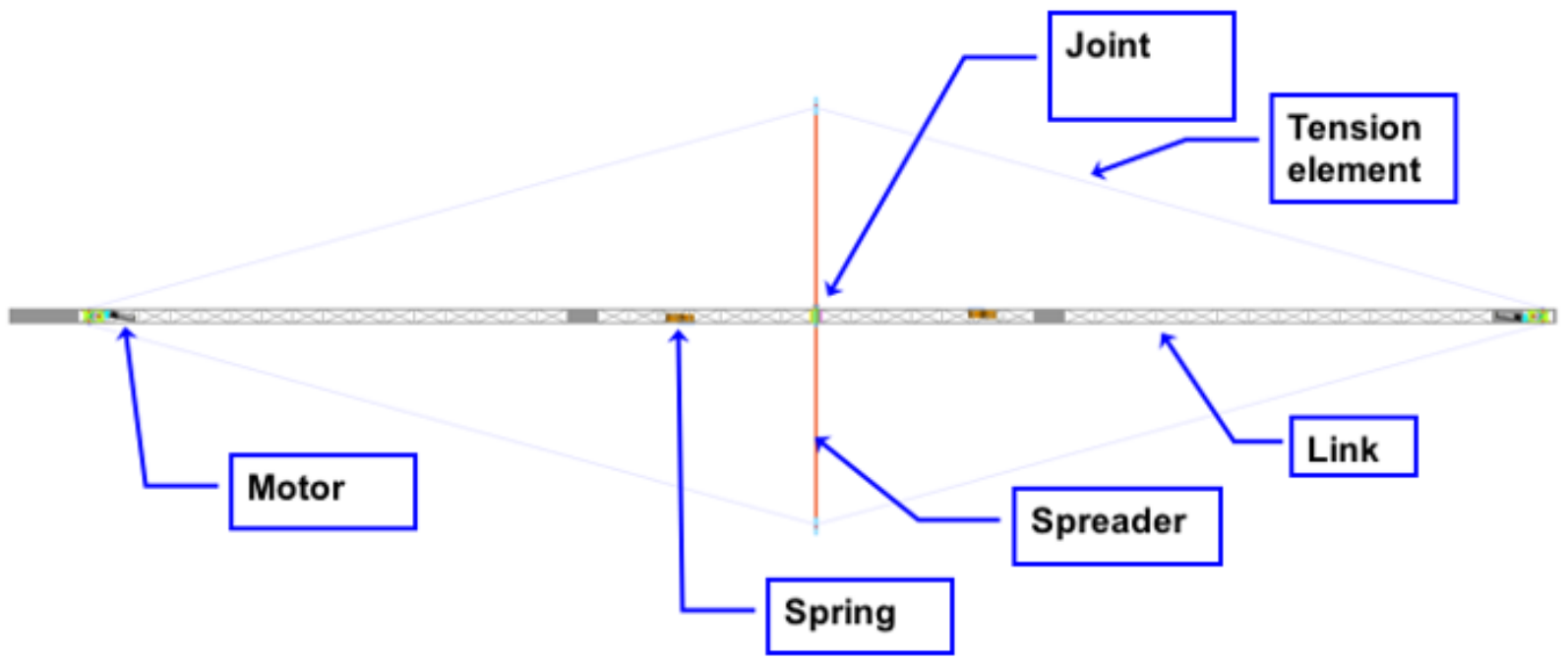

Figure 3. Major components in the first-generation TALISMAN architecture.

The NASA mission and exploration architecture studies show that there is a critical need to be able to maneuver and precisely place payloads to perform space operations involving reusable assets or in-space assembly and construction, as shown in Figure 4.

Two first-generation, full-scale TALISMAN prototypes have been fabricated and were used in a payload maneuvering operation demonstration. The design for the initial TALISMAN application focused on satellite 
Table 2. SEP Tug assembly steps.

\begin{tabular}{|c|c|c|}
\hline Step & Participants & Action \\
\hline 1 & $\begin{array}{l}\text { Left backbone truss (LBT), Left } \\
\text { hand TALISMAN (LHT), Mod- } \\
\text { ular connector on Spacecraft bus }\end{array}$ & Attach stowed deployable LBT to spacecraft bus \\
\hline 2 & $\begin{array}{l}\text { Right backbone truss (RBT), } \\
\text { Right hand TALISMAN (RHT), } \\
\text { Modular connector on Space- } \\
\text { craft bus }\end{array}$ & Attach stowed deployable RBT to spacecraft bus \\
\hline $3 \mathrm{a}$ & LBT, LHT, IPJR, EBW & LHT deploys outer 2 bays of truss \\
\hline $3 \mathrm{~b}$ & & RHT positions IPJR on truss \\
\hline $3 \mathrm{c}$ & & IPJR jigs truss geometry \\
\hline $3 \mathrm{~d}$ & & $\begin{array}{l}\text { RHT retrieves EBW from storage and positions near } \\
\text { truss hinges/telescoping joints }\end{array}$ \\
\hline $3 \mathrm{e}$ & & EBW welds and inspects joints \\
\hline $\begin{array}{l}3 f- \\
N\end{array}$ & & $\begin{array}{l}\text { Repeat steps } 3 \mathrm{a}-3 \mathrm{e} \mathrm{N} \text { times on next two-bays until } \\
\text { truss is completely deployed and rigidized }\end{array}$ \\
\hline $4 \mathrm{a}$ & LBT, SA Modules, LHT, IPJR & LHT grapples IPJR \\
\hline $4 \mathrm{~b}$ & & LHT positions IPJR at SA storage location \\
\hline $4 \mathrm{c}$ & & $\begin{array}{l}\text { IPJR grapples SA module and removes it from storage } \\
\text { site }\end{array}$ \\
\hline $4 \mathrm{~d}$ & & $\begin{array}{l}\text { LHT positions IPJR/SA combination near modular } \\
\text { connector on truss }\end{array}$ \\
\hline $4 \mathrm{e}$ & & IPJR installs SA onto truss modular connector \\
\hline $4 \mathrm{f}$ & & LHT relocates IPJR tool to top of stowed SA module \\
\hline $4 \mathrm{~g}$ & & IPJR grapples deployment fixture at top of SA module \\
\hline $4 \mathrm{~h}$ & & LHT executes straight line tip motion to deploy SA \\
\hline $\begin{array}{ll}4 \mathrm{i}- \\
\mathrm{N}\end{array}$ & & $\begin{array}{l}\text { Repeat steps } 4 \mathrm{a}-4 \mathrm{~h} \mathrm{~N} \text { times until all SA modules have } \\
\text { been attached to and deployed from LBT }\end{array}$ \\
\hline $\begin{array}{l}5 \mathrm{a}- \\
\mathrm{N}\end{array}$ & RBT, RHT, IPJR, EBW & $\begin{array}{l}\text { Repeat all steps in sequence } 3 \text { to deploy and rigidize } \\
\text { the RBT. }\end{array}$ \\
\hline $\begin{array}{ll}6 \mathrm{a}- \\
\mathrm{N}\end{array}$ & RBT, SA Modules, RHT, IPJR & $\begin{array}{l}\text { Repeat all steps in sequence } 4 \text { to attach and deploy } \\
\text { SA modules }\end{array}$ \\
\hline
\end{tabular}

servicing and achieving: high dexterity, a large reach envelope, applying and reacting large tip forces, being able to deploy and restow multiple times, while packaging compactly for launch. ${ }^{18}$ Each of the first-generation TALISMANs has three links with three DOF in the plane of the tendons affording a total reach of 12.0 meters (39.25 feet).

\section{IV.A.2. $L S M S$}

The LSMS is a hybrid between a crane and a robotic manipulator incorporating desirable capabilities of each: the structural efficiency, long reach and large mass lifting capabilities of a crane; and the dexterity, precision and versatile tool use of a manipulator. The LSMS is a versatile and multi-purpose device that was developed to provide a variety of autonomous construction and assembly capabilities such as, unloading landers, lifting and positioning payloads and tools, assembling modules, site preparation, etc. on planetary surfaces. A key feature of the LSMS structural architecture is that it is a tension-stiffened/tendon-actuated manipulator, allowing it to achieve very high structural efficiency. The LSMS was initially used to demonstrate an extensive series of capabilities related to cargo handling and payload manipulation/positioning which are needed to assemble outposts on the surfaces of the Moon and Mars.

A first-generation LSMS was designed, assembled and underwent extensive field testing in June 2008 


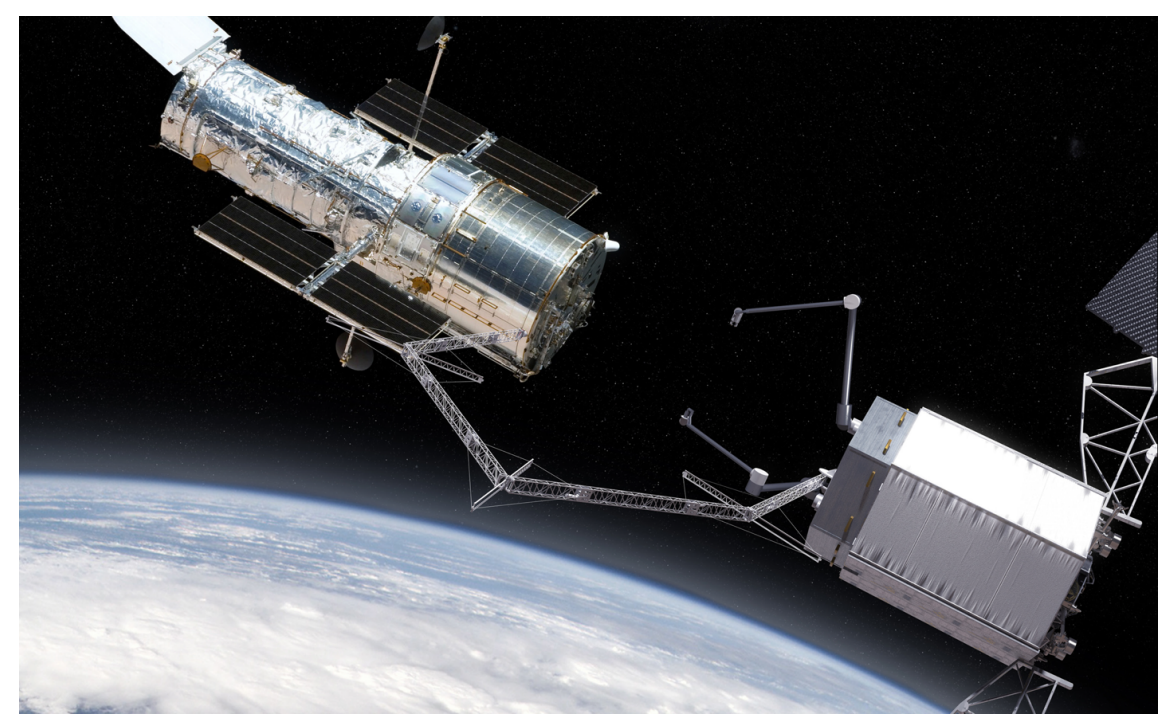

Figure 4. A first-generation TALISMAN supporting autonomous in-space servicing.

(see Figure 5). This version of the LSMS has three DOF provided by waist, shoulder and elbow joints, and three 3.75-meter long links: king post, arm, and forearm. This full-scale LSMS is sized for unloading payloads from the deck of a lander of approximately 6 meters high, while operating from a planetary surface. The first generation LSMS can lift $150 \mathrm{~kg}$ at its wrist on the Earths surface, $500 \mathrm{~kg}$ on Mars, and 1000 $\mathrm{kg}$ on the moon. For unloading cargo or accessing high locations, the arm and forearm can rotate up to reach 9.5 meters above a surface. It can also be configured as a horizontal boom; 3.75 meters tall with a horizontal reach of 7.5 meters. More recently, the LSMS has been used as the surrogate for the TALISMAN in experiments to develop autonomous capabilities for in-space assembly.

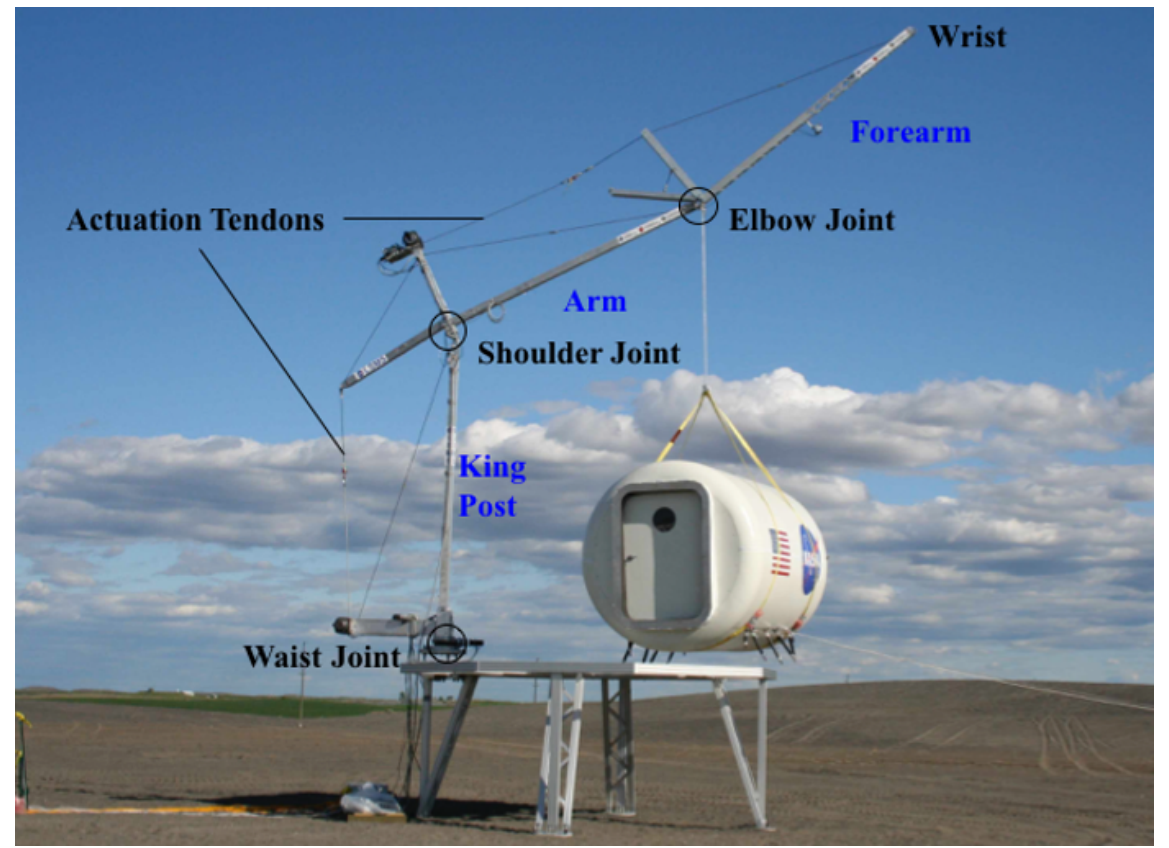

Figure 5. First generation LSMS field test at Moses Lake, WA, June 2008.

\section{IV.A.3. Intelligent Precision Jigging Robot (IPJR)}

The IPJR is a parallel manipulator employing a Stewart platform architecture for manipulation with high 
precision, high stiffness, and high load capacity. ${ }^{19,20}$ Parallel manipulators, such as the IPJR, have several advantages, as illustrated in Figure 6, including: 1) the large payload capacity has the potential to enable positioning of high mass parts; 2) Stewart platforms with sub-micron positioning precision can be built with off-the-shelf linear actuators; and 3) the octahedral topology of Stewart platforms increases stiffness and stability to facilitate joining methods without unwanted vibrations.

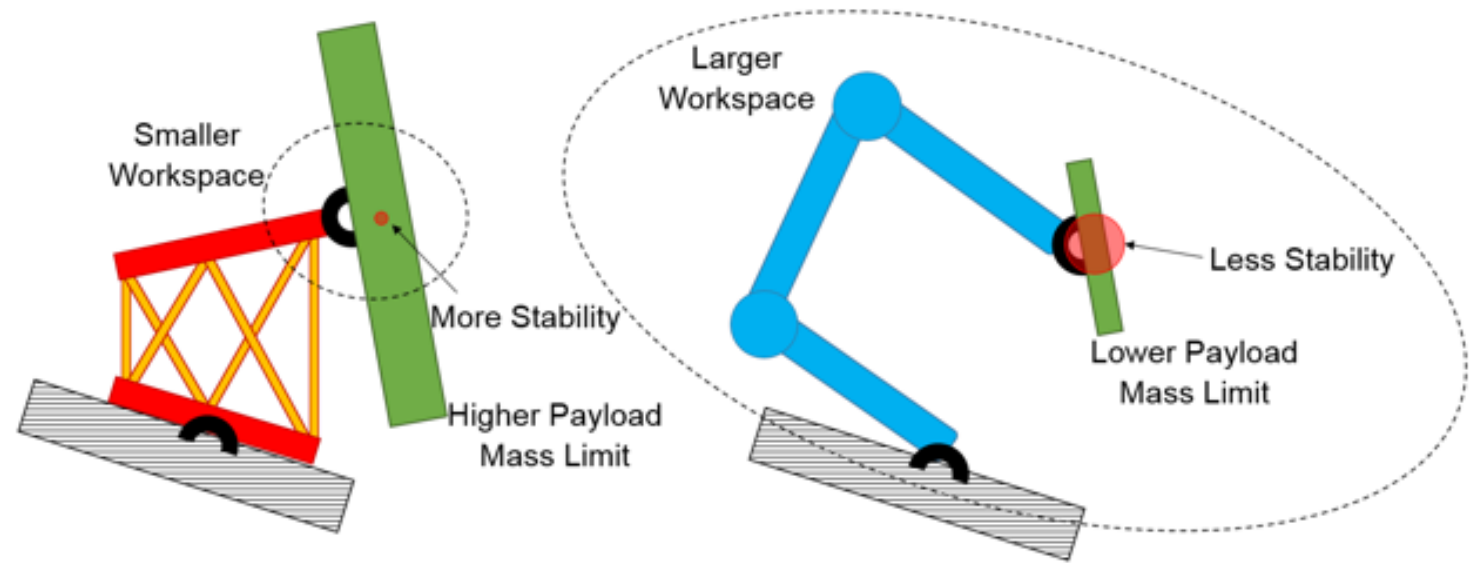

Figure 6. Conceptual comparison between parallel manipulators (left) and serial manipulators (right). The dotted line indicates the range of motion.

The IPJR was designed primarily to position one object relative to another with higher precision than can be achieved by either the LSMS or the TALISMAN. The IPJR does this through the use of grippers located on both ends of the Stewart platform (hereafter referred to as the top plate and the bottom plate), as shown in Figure 7. The grippers are modular components that can be easily changed, which led to the use of two configurations: 1) the TALISMAN tool repositioning configuration, capable of grasping the truss and 2) the TALISMAN end effector and the SA assembly configuration, capable of positioning SAs for assembly to the truss.

The truss gripper employed linear actuators to capture the truss. To facilitate truss capture, brackets with wide openings captured the three struts emanating from the mounting node and guided them into strut-sized channels. Once the IPJR was seated, three linear actuators pushed pins to lock the struts in three of the brackets. This configuration created a triangular base, locking the bottom plate to the truss. The TALISMAN end-effector was fitted with a truss node, allowing the truss gripper to be reused. The SA gripper employed two linear actuator grippers on its top plate to hold a panel over each bay, each with features to correct alignment as the gripper closed on the panel. The IPJR grasped the truss using brackets which guided the struts into the capture envelope, then locked onto the struts with extended pins. Both types of grippers used Actuonix ${ }^{\mathrm{a}}$ actuators $^{21}$ with a $100-\mathrm{mm}$ stroke.

The IPJR required a range of motion suitable for positioning SA panel mockups that spanned two adjacent truss bays while it was attached to a truss node located between the bays. The range of motion required the top plate to move up to $200 \mathrm{~mm}$ on a plane parallel to the truss bays, and $100 \mathrm{~mm}$ normal to the plane. This range of motion was also sufficient for enabling the IPJR to grasp the TALISMAN while attached to the truss, and to execute the tool repositioning steps during a TALISMAN demonstration. The Stewart platform on the IPJR was designed to meet these goals, and could rotate more than 45 degrees on each axis. This motion was driven by six Actuonix actuators with a $200-\mathrm{mm}$ stroke, attached to ball joints located on both ends.

The IPJR achieved extended mobility with the assistance of the LSMS. As described previously, the IPJR could grasp the TALISMAN and be moved while attached. To be moved by the LSMS, the IPJR-to-LSMS interface used conical posts that slotted into grooves on the end-effector. In lieu of a gripper, the IPJR positioned these conical posts into a capture volume located on the LSMS end-effector, then settled into the grooves that locked as weight was applied when the IPJR was lifted.

The electronics for the IPJR actuators were split between the upper and lower plates. Each plate housed the electronics for three Stewart platform actuators and the grippers located on that plate. This reduces

${ }^{\text {a }}$ This is not an endorsement by the National Aeronautics and Space Administration (NASA). 

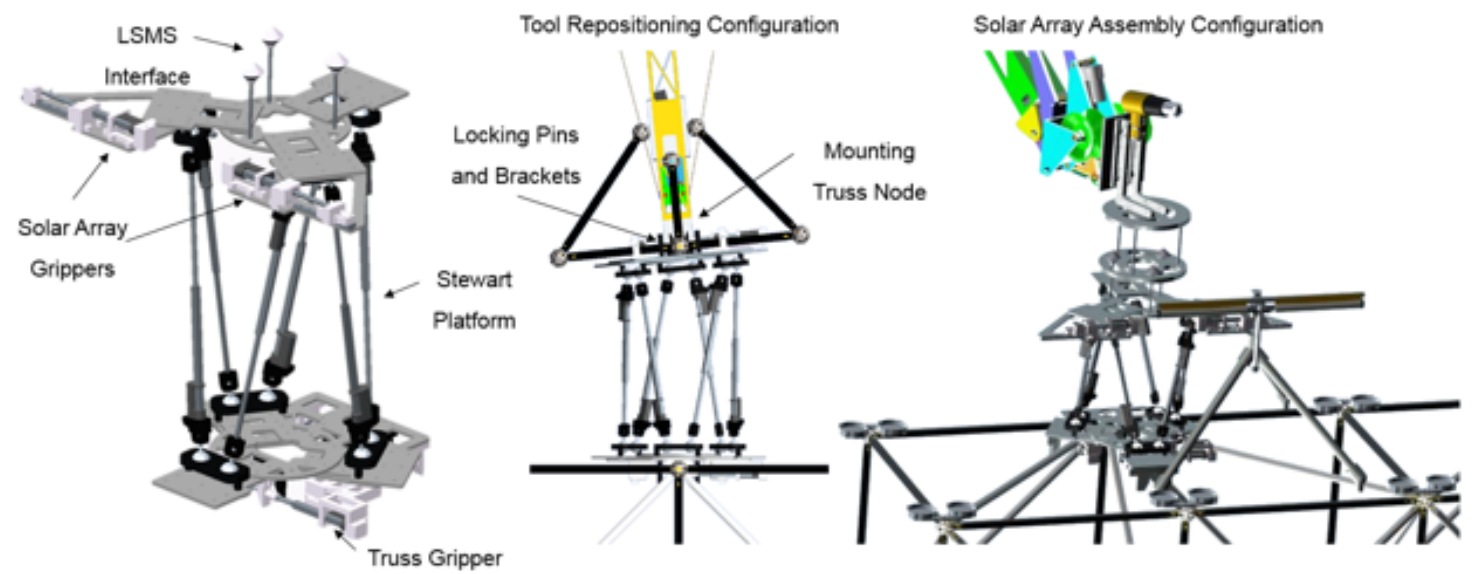

Figure 7. Left: IPJR diagram displaying interfaces to SAs, truss, and LSMS. Center: IPJR in tool repositioning configuration. Right: IPJR in SA assembly configuration, attached to truss and LSMS.

the amount of cabling going between the plates and limits the number of actuators operated by each plate. A single power cable connected both plates to a power supply in the workspace. An Arduino ${ }^{22}$ Mega $2560^{\mathrm{b}}$ controlled each plate, and received commands via radio.

\section{IV.B. Limitations and Approaches to Ground Testing for Zero-G Operations}

\section{IV.B.1. Limitations on Performing Zero-g Operations using TALISMAN}

The TALISMANs are not able to support themselves in a $1 \mathrm{~g}$ environment, and must operate in the plane of the flat floor. Thus, there are limitations to some of the operations they can perform. For example, when a backbone truss must be deployed or constructed in space, the operational location of the TALISMAN tip would most likely be in the center of the truss batten frame. However, grappling this location is not possible with the TALISMAN since the plane of the floor is in line with the lower surface of the truss, as shown in Figure 8. Thus, for any ground operational demonstrations requiring truss deployment or construction operations, the TALISMAN will not be able to exactly duplicate the flight operations. Other flight operations where something would be attached to the center of the truss batten frame, such as connecting a SA module or positioning an IPJR, would also not be directly possible. In some cases, special fixtures and separate tests might be performed to demonstrate representative flight operations. Using a turntable at the base of the truss is being considered to add a rotational DOF to provide increased versatility, and to simplify operations for the TALISMANs and associated tools. However, this DOF also cannot be replicated on the flat floor, so all faces of the truss would not be accessible to TALISMAN to demonstrate flight operations.

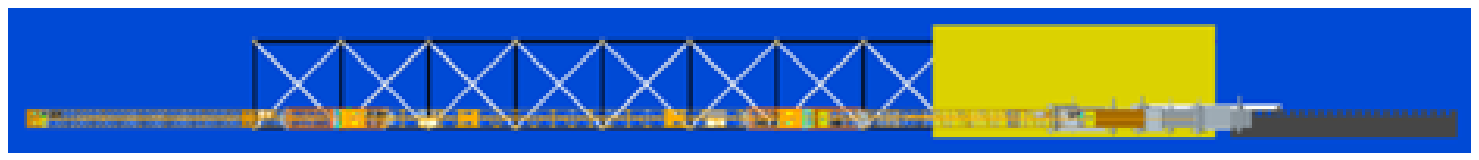

Figure 8. TALISMAN on flat floor is in the same plane as the truss lower surface.

\section{IV.B.2. Similarity of TALISMAN and LSMS for Performing Operations}

In order to replicate the in-space operations as closely as possible in the ground test series, the LSMS was used as a surrogate for the TALISMAN in one of the test series. The operational similarity between the two manipulators must be established to validate the use of LSMS as a surrogate. This similarity should include tip motion capability, range of motion, and tip control. A list of similarity attributes and summarizes the capabilities of the LSMS and TALISMAN is shown in Table 3. Both the LSMS and the TALISMAN share the same robotic architecture: they are tendon actuated and stiffened manipulators, with 1-DOF joints, axially loaded truss links and use spreaders to offset the cable tension force from the hinge (rotation) axis to reduce

\footnotetext{
${ }^{\mathrm{b}}$ This is not an endorsement by the National Aeronautics and Space Administration (NASA).
} 
moments at the joints. Although the two manipulators use different motors, gearboxes, cables, and hoists versus capstans, the actuation control architecture is the same and any differences in implementation are not relevant since ultimately, the tip motion and accuracy are solely determined by the closed-loop feedback control system. In both prototype manipulators, a Vicon ${ }^{23}$ system $^{\mathrm{c}}$ is used in the lab environment to track manipulator motion and drive the tip position. In the plane of the cables, the TALISMAN has twice the number of DOF and thus more dexterity. However, the LSMS is still able to execute straight line tip motion over several meters. Another benefit of using the LSMS when performing vertical operations is its large tip force capability. In summary, the LSMS can be thought of as a reduced capability (in terms of DOF, poses and operational capabilities) version of the TALISMAN. Thus, if the LSMS can perform the proposed test operations, then the TALISMAN will be even more capable of performing those same operations. The similarity of attributes listed in Table 3 verifies that the LSMS is a valid surrogate for the TALISMAN in the ground operational tests that were performed.

Table 3. LSMS and TALISMAN similarity established for operations.

\begin{tabular}{|c|c|c|c|}
\hline Parameter & LSMS & $\begin{array}{l}\text { TALISMAN on Flat } \\
\text { Floor }\end{array}$ & Comment \\
\hline $\begin{array}{l}\text { Actuation Architec- } \\
\text { ture }\end{array}$ & Tendon actuated & Tendon actuated & Identical \\
\hline Design application & Long-reach manipulation & Long-reach manipulation & Identical \\
\hline $\begin{array}{l}\text { DOF in plane of ten- } \\
\text { dons }\end{array}$ & 2 & 4 & $\begin{array}{l}\text { TALISMAN has } \\
\text { higher capability }\end{array}$ \\
\hline Total Reach & 7.5 meters horizontal & 20 meters & $\begin{array}{l}\text { TALISMAN has } \\
\text { higher capability }\end{array}$ \\
\hline $\begin{array}{l}\text { Total length of tip } \\
\text { straight line motion }\end{array}$ & Approximately 9.5 meters & Approximately 17.0 meters & $\begin{array}{l}\text { TALISMAN has } \\
\text { higher capability }\end{array}$ \\
\hline Closed Loop Control & Vicon system & $\begin{array}{l}\text { Vicon system initially, then } \\
\text { vision }\end{array}$ & Identical \\
\hline $\begin{array}{l}\text { Positioning Accu- } \\
\text { racy and resolution } \\
\text { at tip }\end{array}$ & $\begin{array}{l}5 \mathrm{~mm} \text { (all axes) } 2 \mathrm{~mm} \text { pos- } \\
\text { sible (slow) }\end{array}$ & $\begin{array}{l}5 \mathrm{~mm} \text { (all axes) } 2 \mathrm{~mm} \text { pos- } \\
\text { sible (slow) }\end{array}$ & Identical \\
\hline Tip Force Capability & 330 lbf (operational load) & 15 lbf (operational load) & $\begin{array}{l}\text { LSMS higher; allows } \\
\text { IPJR and truss bays } \\
\text { to be lifted in } 1 \mathrm{~g}\end{array}$ \\
\hline Batten Frame Reach & $\begin{array}{l}\text { Reach anywhere in batten } \\
\text { cross-section }\end{array}$ & $\begin{array}{l}\text { Limited to the bottom } \\
\text { truss longeron }\end{array}$ & $\begin{array}{l}\text { LSMS can replicate } \\
\text { flight operations }\end{array}$ \\
\hline
\end{tabular}

\section{IV.B.3. Enabling the LSMS Access at a Range of Angles}

Due to the LSMS being mounted on the laboratory floor, and the assembly workspace being fixed, an extra DOF was required to enable the LSMS to access the SEP tug assembly at a range of angles. This was achieved by placing a motorized and controllable turntable beneath the assembly site. The turntable was driven by a direct current motor connected to an Arduino $\mathrm{Uno}^{\mathrm{d}}$, controlled by serial communications using a radio.

\section{IV.C. Controls and Algorithms Development and Applications}

In order to perform both the TALISMAN truss deployment and IPJR positioning demonstration and the IPJR SA assembly demonstration, a central computer employed an assembly sequence and control algorithm to enable autonomous assembly with error detection and correction. The description of this algorithm follows, with specific implementation details.

\footnotetext{
${ }^{\mathrm{c}}$ This is not an endorsement by the National Aeronautics and Space Administration (NASA).

${ }^{\mathrm{d}}$ This is not an endorsement by the National Aeronautics and Space Administration (NASA).
} 
Sequential Assembly with State Estimation: $A, \bar{X}_{0}, \Sigma_{0}$

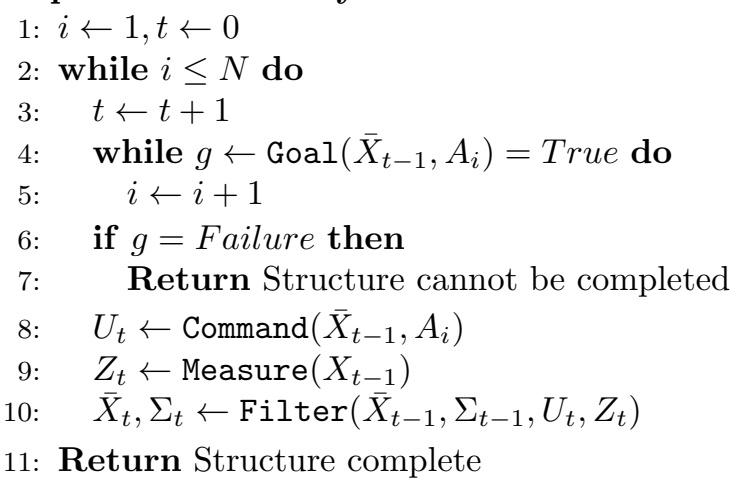

Figure 9. Algorithmic description of assembly sequence.

To perform the steps associated with both demonstrations, the system must maintain an updated state estimate of the entire structure including the positions of all of the robots. The current algorithm developed for this effort is presented in Figure 9. Starting with the assembly steps $A$, and an initial estimate of the states of the parts and robots $\bar{X}_{0}$ with uncertainty $\Sigma_{0}$, this algorithm iterates over each step until each goal is met. Each iteration checks for goal status, commands the robots, then measures and updates the state estimates. In general, at time $=t, S_{t}=\left[S_{1} \ldots S_{\sigma}\right]$ contains the state of the structure, where each state includes position, orientation, and assembly status ${ }^{\mathrm{e}} . R_{t}=\left[R_{1} \ldots R_{\rho}\right]$ contains the state of the robots, with each state containing position, orientation, and other status details. The combined state is $X_{t}=\left[S_{t}, R_{t}\right]$. The state must be estimated as $\bar{X}_{t}$ with an uncertainty term $\Sigma_{t}{ }^{\mathrm{f}}$. The control vector $U_{t}=\left[U_{1} \ldots U_{\rho}\right]$ contains all commands issued to the robots. $Z_{t}$ contains all measurements of the structure and the robots. $N$ is the number of steps needed to complete the structures,$i$ the step index, $A_{i}$ the step goal, and $A=\left[A_{1} \ldots A_{N}\right]$. $\operatorname{Goal}\left(\bar{X}_{t-1}, A_{i}\right)$ is a function that returns True if the step goal has been achieved, False if not, and Failure if the goal cannot be met, which permits termination of the algorithm. Command $\left(\bar{X}_{t-1}, A_{i}\right)$ commands the robots and returns $U_{t}$. Command handles any required adjustments. Measure $\left(X_{t-1}\right)$ collects measurements from the environment, and Filter $\left(\bar{X}_{t-1}, \Sigma_{t-1}, U_{t}, Z_{t}\right)$ estimates the state. The assembly sequence starts with a priori estimates for the state, covariance, and initial controls.

The implementation of Goal compared relative positions between objects; if the relative position and orientation is within the permissible error boundaries on all six axes, a 5 second timer begins to prevent false positives through jitter. If error remains bounded after 5 seconds, Goal returns True. Teleoperation was necessary to train the relative positions and orientations for objects when in their goal poses. Each step had an acceptable per-axis translation error ranging from $3 \mathrm{~mm}$ to $5 \mathrm{~mm}$ and 3 degrees to 10 degrees. All robots were capable of sub-millimeter precision however a significant time penalty would have been incurred if this was made a requirement.

The Measure function recorded Vicon ${ }^{\mathrm{h}}$ position and rotation data for each object in the scene: each plate of the IPJR, each panel, the truss, and depending on the experiment, each link of each TALISMAN, or the end effector of the LSMS. Eight Vicon ${ }^{23}$ Bonita and five Vicon Vero cameras were stationed around two TALISMANS in the truss deployment workspace, and the eight Bonita cameras were stationed around the truss in the SA assembly workspace. Each tracked object had at least five 14-mm retroreflective markers spread over its visible surface. The bottom plate of the IPJR had eight markers due to it being partially obscured by the top plate. The standard deviations of the measurement noise of a still object were estimated to be $0.5 \mathrm{~mm}$ and 0.5 degrees in the translation and rotation axes.

The Vicon ${ }^{23}$ Tracker software lacks an onboard state transition function, meaning that an additional filter making use of a transition function was used to improve the estimate. Filter implements the Extended Kalman Filter ${ }^{24}$ to improve the estimates of the positions and rotations of each object given its current estimate, covariance, and controls. The control vector is used to predict where the objects would have moved, including parts affixed to moving robots. Still objects are assumed to stay still, and very small

e Specific details will vary with application.

$\mathrm{f}_{\Sigma_{t}}$ may represent a covariance matrix for Kalman filters, or a particle set for particle filters.

$\mathrm{g}_{N}$ is distinct from the part count due to intermediate steps.

${ }^{\mathrm{h}}$ This is not an endorsement by the National Aeronautics and Space Administration (NASA). 
standard deviations: $0.1 \mathrm{~mm}$ and 0.1 degrees are specified, small enough to prevent measurement jitter from steering the estimate too much, while large enough to prevent singularities in the filter calculation. The filter favors measurements of moving objects to account for variations in motor output, assigning transition standard deviations of $4 \mathrm{~mm}$ and 4 degrees.

The Vicon ${ }^{\mathrm{i}}$ measured complete states for all parts and most robots. However, the Vicon could measure only the end-effector and part of the last link on the LSMS; the other two links were estimated from a state model. The base location of the LSMS was estimated by finding the most likely common center over a sweeping motion. Inverse kinematics then determined all joint positions using the measured base position and end effector state.

The Command function has distinct implementations for each of the robots in the workspace. The turntable used proportional control to rotate, slowing proportionally within 5 degrees of the goal. The LSMS implementation used saturated proportional control to drive each individual motor, also slowing proportionally within 5 degrees of the goal. The IPJR implementation used the inverse Jacobian of the plate motion to plan a linear path between the current state and the desired state, and required one of the two plates to be fixed and the other to be free, so that the system was not underactuated. Saturated proportional control started slowing the IPJR within $20 \mathrm{~mm}$ of its goal. The TALISMAN implementation also made use of the inverse Jacobian to plan straight line motions of the end effectors, and used proportional control to slow when the total angle error for the links was 5 degrees from the goal.

\section{IV.D. TALISMAN Truss Deployment and IPJR Positioning Demonstration}

The purpose of the TALISMAN ground demonstration was to validate the maturity of key LaRC ISA capabilities for performing operations applicable to assembling a SEP tug in space. The demonstration was held on December 13, 2016 at LaRC and took about 90 minutes to complete. The two principal robotic capabilities demonstrated were operations associated with: 1) long-reach grappling and manipulation using the TALISMAN, and; 2) precision grappling and positioning using the IPJR . The objectives of this demonstration were:

1. Demonstrate TALISMAN and IPJR robotic operational capabilities and perform operations representative of assembling a large SEP tug in space.

2. Measure and validate the accuracy of the TALISMAN in following a prescribed path that represents deploying truss bays.

3. Measure and validate the accuracy of the TALISMAN in positioning the IPJR within its capture envelope at multiple locations in the work space and demonstrate IPJR dexterity at grappling objects: a truss and a fixture on the end of the TALISMAN.

\section{IV.D.1. Demonstration Set Up and Execution Plan}

The laboratory demonstration included the following hardware (see Figures 10 and 11): two TALISMANs, an IPJR, a fixed-length backbone truss mockup, and a simple canister at the base of the truss (three bays long). The truss had 11 bays with three bays initially contained in the canister. The complete sequence of steps that were executed during the first demonstration are listed in Table 4.

\section{IV.D.2. Demonstrate Robotic Capabilities to Perform Representative Flight Mission Operations}

A fundamental objective of the TALISMAN demonstration was to demonstrate TALISMAN capabilities to perform tasks that are generally consistent with both NASA ISA concepts and assembling a large SEP tug. Thus, two tasks representative of what would be required of the TALISMAN robotic arms on orbit were chosen for demonstration. The first task was the simulated deployment of a stowed truss and the second task was repositioning the IPJR jigging robot at locations along the length of the previously deployed truss.

The complete sequence of continuous operations listed in Table 4 was successfully executed without error. Both TALISMAN arms and the IPJR successfully moved to all pre-determined set points, where planned pauses were executed after metrology confirmed each component was at the set point within specified error limits. No direct operator intervention was required during the execution of this phase of the demonstration.

\footnotetext{
${ }^{\mathrm{i}}$ This is not an endorsement by the National Aeronautics and Space Administration (NASA).
} 
Table 4. TALISMAN demonstration sequence.

\begin{tabular}{|l|l|l|}
\hline Step & Participants & Action \\
\hline 1 & LHT, Backbone Truss & LHT attaches to truss at bay location near tip. \\
\hline 2 & LHT, Backbone Truss & $\begin{array}{l}\text { LHT executes linear tip motion and extracts two bays } \\
\text { of truss from canister (leaving one bay still in the can- } \\
\text { ister), then holds truss in place. }\end{array}$ \\
\hline 3 & RHT & RHT moves its tip to proximity of IPJR \\
\hline $4 \mathrm{a}$ & RHT, IPJR, Backbone Truss & IPJR grapples fixture on RHT \\
\hline $4 \mathrm{~b}$ & IPJR, Backbone Truss & IPJR releases from truss \\
\hline 5 & RHT, IPJR & $\begin{array}{l}\text { RHT moves IPJR to new grapple location on bay near } \\
\text { the end of the truss }\end{array}$ \\
\hline $6 \mathrm{a}$ & RHT, IPJR, Backbone Truss & IPJR grapples truss \\
\hline $6 \mathrm{~b}$ & RHT, IPJR & IPJR releases from RHT \\
\hline $6 \mathrm{c}$ & RHT, Backbone Truss & $\begin{array}{l}\text { RHT moves to position approximately } 1 \text { meter away } \\
\text { from truss }\end{array}$ \\
\hline $6 \mathrm{~d}$ & RHT, IPJR, Backbone Truss & RHT moves tip to proximity of IPJR \\
\hline $6 \mathrm{e}$ & RHT, IPJR & IPJR grapples RHT \\
\hline $6 \mathrm{f}$ & RHT, IPJR & IPJR releases truss \\
\hline $6 \mathrm{~g}$ & RHT & $\begin{array}{l}\text { RHT moves to position approximately } 1 \text { meter away } \\
\text { from truss. Steps } 6 \mathrm{c} \text { through } 6 \mathrm{~g} \text { will be repeated a } \\
\text { minimum of } 3 \text { times to establish positioning accuracy } \\
\text { and precision. }\end{array}$ \\
\hline 7 & & $\begin{array}{l}\text { After minimum of } 3 \text { repeat cycles of } 6 \mathrm{c} \text { - 6g, execute } \\
\text { this step and proceed to steps } 8 \text { and } 9\end{array}$ \\
\hline 8 & RHT & RHT returns to neutral/parked pose/position \\
\hline 9 & LHT & LHT returns to neutral/parked pose/position \\
\hline & & RHT, Backbone Truss \\
\hline
\end{tabular}

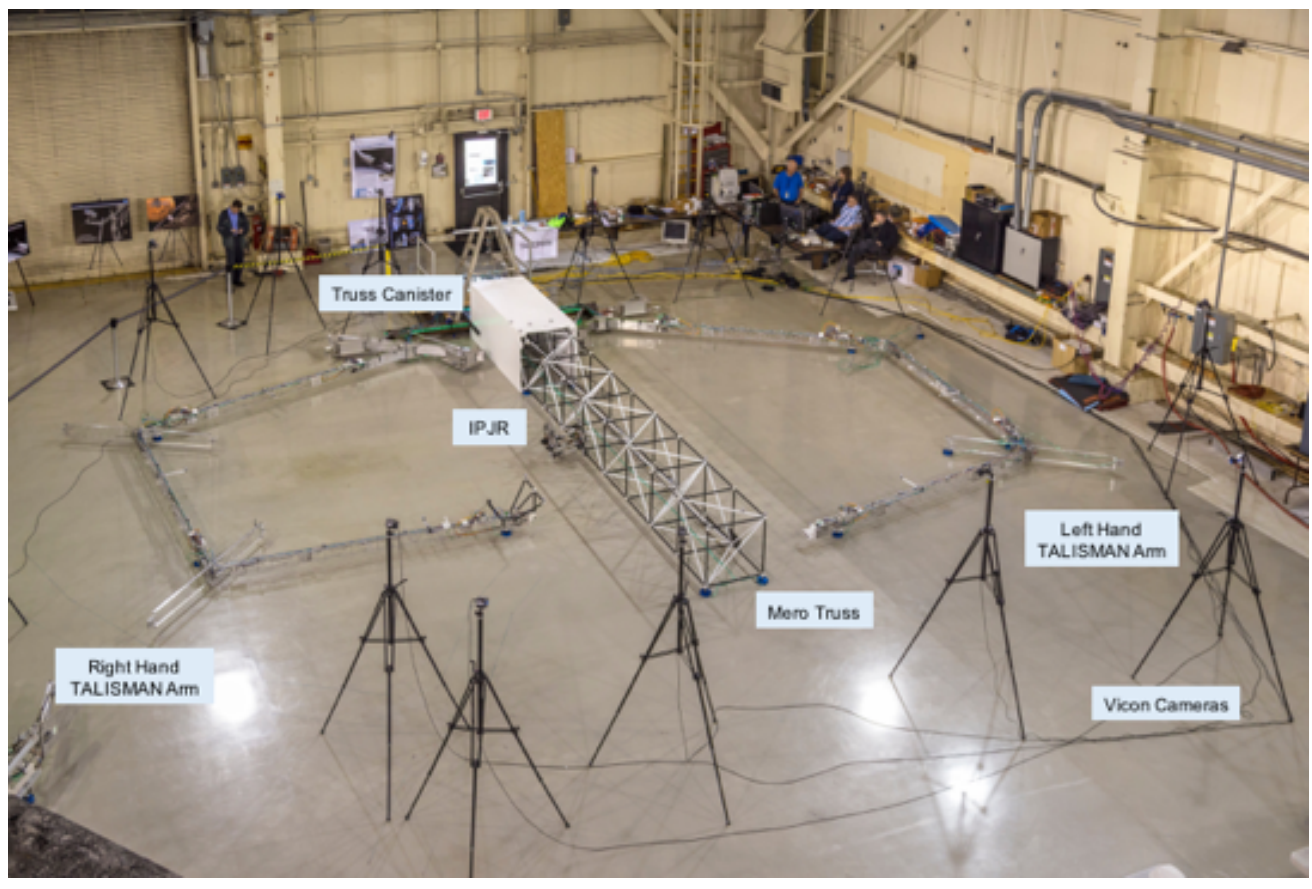

Figure 10. TALISMAN demonstration hardware setup. 


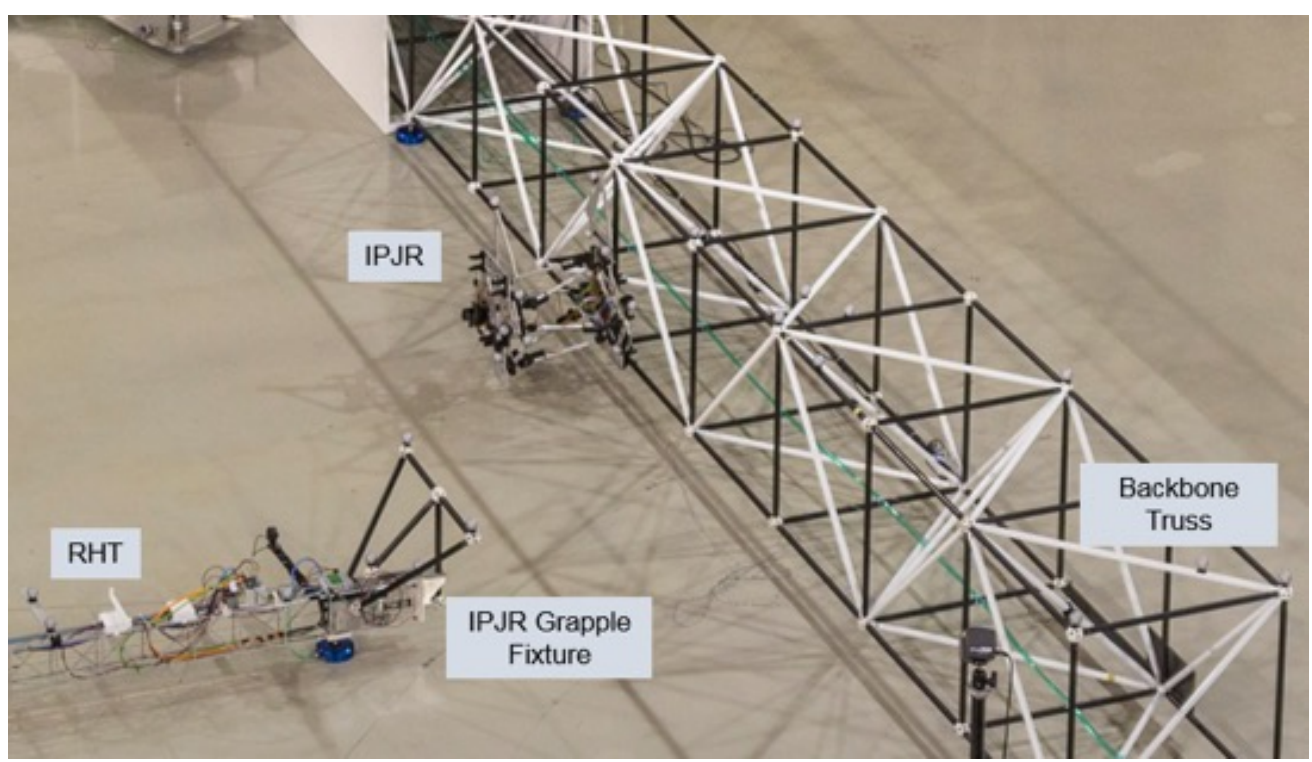

Figure 11. Close up of IPJR attached to initial location on truss bay.

The LHT arm was successful in simulating the deployment of the mockup truss on its first attempt. Three truss bays were stowed in the canister prior to test execution. In this part of the demonstration, the LHT grappled the truss, using a magnetic gripper, and then pulled two truss bays out of the canister. Once the truss was fully deployed, the RHT arm was able to position itself to capture the IPJR to successfully mate with and move the IPJR to a new location on the truss. These actions were executed with pre-planned way points, using the Vicon ${ }^{\mathrm{j}}$ vision system for error correction without operator intervention. Both video and time-lapse photography documented the execution of the complete demonstration.

\section{IV.D.3. Validate TALISMAN Accuracy: Following a Prescribed Linear Path}

One of the main goals of the TALISMAN demonstration was the linear deployment of the truss. This capability is important because failure to draw the truss straight out from the canister, while in space, could lead to binding or impingement within the deployment housing jeopardizing the mission. For the purposes of a successful demonstration, the objective was for the LHT arm to pull the truss bays out of the canister in a straight line within 1.0 inch of a linear path perpendicular to the plane of the canister opening. The accuracy of the TALISMAN in following this linear path, while deploying the truss bays, was measured using the Vicon vision system. The tip position of the LHT was recorded and compared to a theoretical straight-line path from which deviation was computed. The resulting motion of a marker on the tip of the truss was also tracked as it was deployed by the LHT. The motion of the truss tip is presented in Figure 12.

From the horizontal axis in Figure 12, it is observed that 54.1 inches of truss structure was deployed during the demonstration. Since the bay size for the truss is 27.8 inches, this equates to 1.95 truss bays. The deviation of the truss tip from a straight line is represented by data values on the Y-axis in Figure 12. At a gross level, this test was successful: the truss deviated between +0.91 inches and -0.47 inches during the deployment which is within the initial goal for the demonstration. A detailed explanation of tip movement follows.

The LHT grapples the truss initially at time $=0$. To overcome a loss of tension caused by the magnetic grapple, the LHT is then commanded to add tension to all of the cables which results in the tip to deviate by -0.47 inches. The LHT then begins deploying the truss and tracks linearly for approximately the first third of the extension, rising up to the first local maximum at +0.83 inches and then ending only +0.43 inches from the straight line. The motion from there was the result of a final script command to the LHT to go to a final taught point.

Review of the data closely reveals the potential for the TALISMAN tracking to be much more accurate; the variability in the positioning noted in Figure 12 is primarily due to the accuracy of the specified pre-

${ }^{\mathrm{j}}$ This is not an endorsement by the National Aeronautics and Space Administration (NASA). 


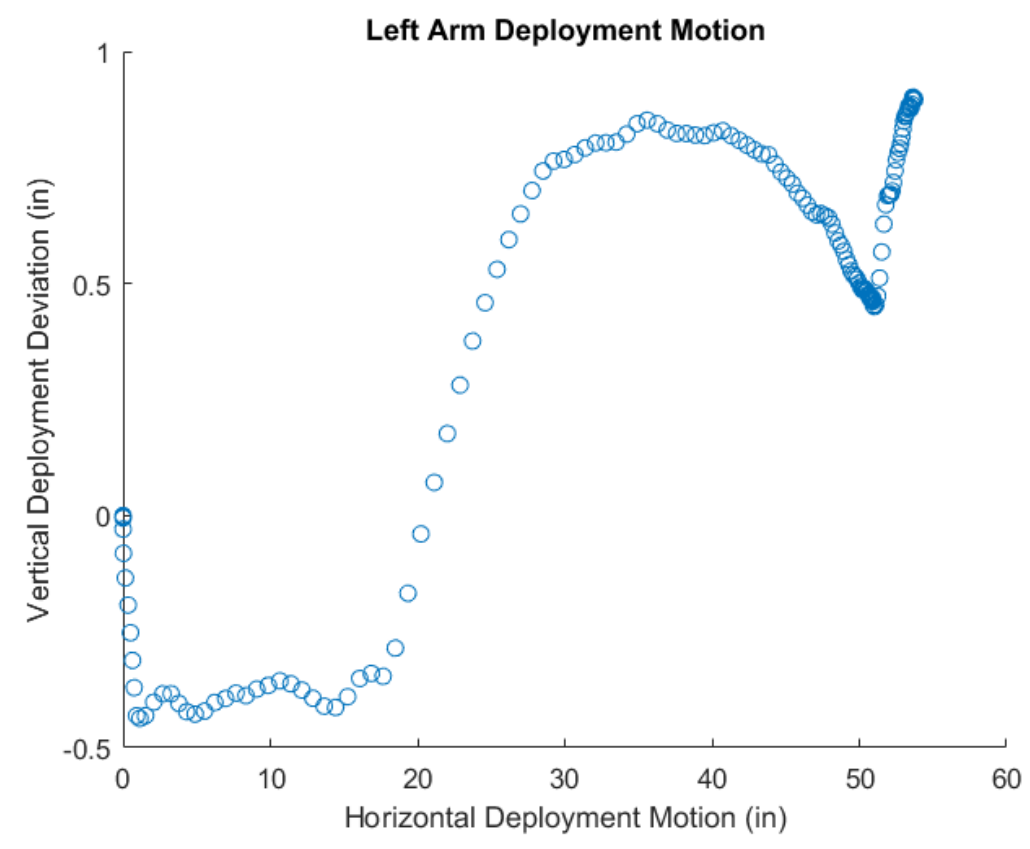

Figure 12. Truss Tip Deviation from Linear Motion (vertical axis exaggerated for visibility).

planned waypoint locations and the control logic used to maneuver the arm between points. Examination of the data suggest that the TALISMAN arm maneuvered between the pre-determined way points very accurately, but these way points did not accurately represent the desired straight-line path. Causes for this include: the final deployed truss taught point was trained by visual estimation; measured positions on both the truss and canister are determined from Vicon ${ }^{\mathrm{k}}$ measurements of visual markers aligned with each objects features; and the linearity of the path generated by the control logic (Inverse Jacobian) is affected by the accuracy of the model. In conclusion, the TALISMAN has the ability to track a specified path very accurately, but in this demonstration, the taught points and path generation routines forced the LHT to track non-optimum paths. However, the LHT did meet the performance goals for the demonstration and the test was successful.

\section{IV.D.4. Validate TALISMAN Positioning Accuracy and IPJR Dexterity}

The second main objective was demonstrating the positioning accuracy of the TALISMAN and the ability of the IPJR to grapple the truss. The accuracy of the TALISMAN in positioning the IPJR was measured using the Vicon vision system. The IPJR has a limited envelope for grappling the truss, and the TALISMAN must consistently be able to position the IPJR to accommodate its capture envelope. The capture envelope for the IPJR results in a 6-inch by 6-inch square capture box (in the plane of the floor) for the RHT. During the demonstration, the RHT successfully placed the IPJR in its capture envelope, as was demonstrated by the IPJR grappling the truss without further motion required by the RHT. Subsequent to the demonstration, several trials were performed and data collected that measured the accuracy of placing the IPJR in its 6-inch by 6 -inch capture box.

A series of trials were performed, starting with the IPJR attached to the RHT, and the RHT tip at an approach point at least 20 inches from the center of the capture box. The RHT would then move the wrist to the center of the capture box (using guidance from the Vicon system) and park. Next, the IPJR would grapple the truss, release from the RHT, and the RHT would move back to the approach point. This process was repeated ten times, and the position of the RHT wrist within the IPJR capture box was measured using the Vicon system. The resulting gross motion of the RHT wrist for the repeated trials is shown in Figure 13.

In Figure 13, the RHT begins at an approach point. The motion for a total of 10 repetitions are shown

\footnotetext{
${ }^{\mathrm{k}}$ This is not an endorsement by the National Aeronautics and Space Administration (NASA).
} 
where the RHT wrist moves from the approach point into the capture box, with the target being the exact center of the box. Control logic, based on predefined TALISMAN joint angles, was used to drive the RHT to an initial set of joint angles based on a global reference frame (shown in green in Figure 13). Feedback information, provided by the Vicon system, was then used to update the actual position of the TALISMAN. From this position, the TALISMAN employs endpoint control to drive the RHT wrist to its final location in the capture box (shown in blue in Figure 13). Endpoint control is direct proportional control of the angles without the use of inverse kinematics; this leads to curvature in the final approach.

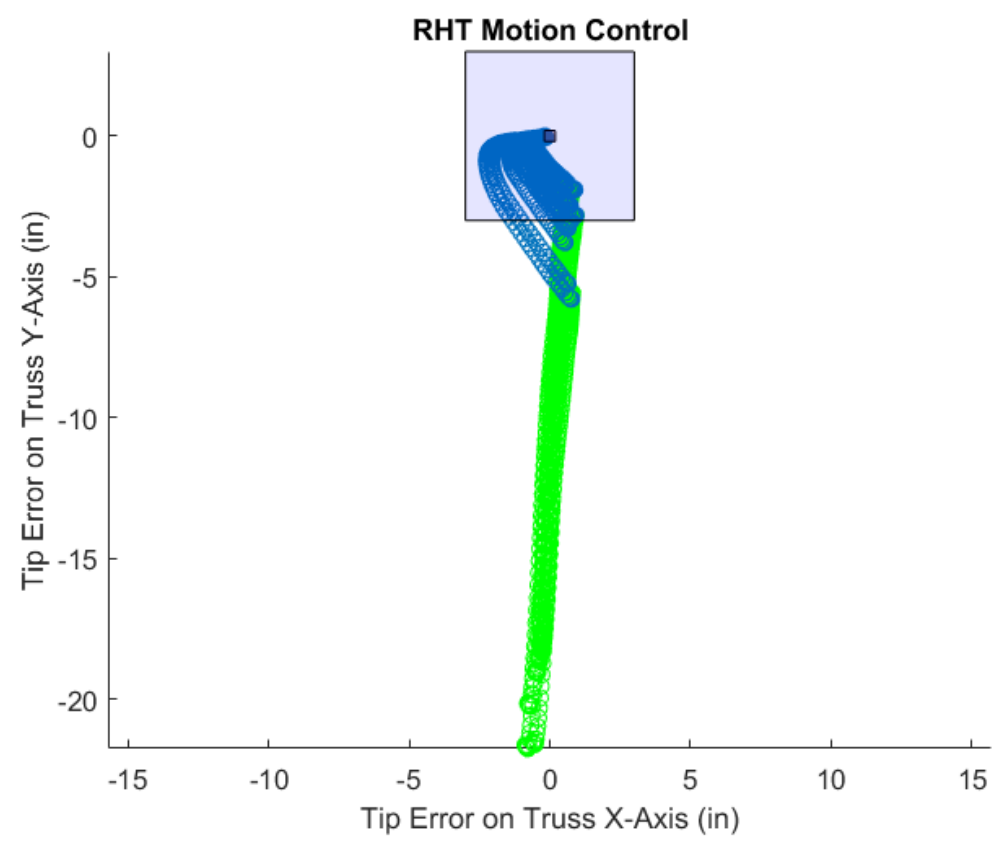

Figure 13. Tracking gross motion of TALISMAN RHT wrist to IPJR capture box.

The trials shown on Figure 13 demonstrate that the RHT easily met the objective of placing its wrist in the predefined capture box. Using the Vicon ${ }^{1}$ feedback, the RHT was able to consistently place the wrist within a $10 \mathrm{~mm} \times 10 \mathrm{~mm}$ box at the center of the 6 -inch by 6 -inch capture box, as shown in Figure 14 . The repeatability and accuracy of wrist placement illustrated in Figure 14 demonstrates the very high motor control capability inherent in the TALISMAN, and the high levels of accuracy and precision that can be achieved with a long-reach tendon actuated manipulator.

In all trials, the RHT located its wrist in the IPJR capture box, and the IPJR subsequently successfully grappled either the truss or the TALISMAN with no correction required by the TALISMAN validating the IPJR dexterity.

\section{IV.E. IPJR Solar Array Assembly Demonstration}

The purpose of the IPJR solar array assembly demonstration was to validate the maturity of key LaRC ISA capabilities for performing operations applicable to assembling a SEP tug in space. The demonstration was carried out in three phases in 2016 at LaRC, and took approximately ten hours to complete. During the course of the demonstration, two complete arrays and one single panel were assembled, totaling nine panels. This demonstration had two primary goals: 1) successfully join a set of the SA modules to the truss, and 2 ) successfully deploy all SA panels after the modules were joined to the truss. The secondary goal was to ensure that all nine panels were positioned within $5 \mathrm{~mm}$ and 3 degrees on each axis (totaling $8.7 \mathrm{~mm}$ and 5.3 degrees), measured after the IPJR released the panels.

\section{IV.E.1. Demonstration Set Up and Execution Plan}

The laboratory demonstration included the following hardware: the LSMS, an IPJR, a backbone truss

\footnotetext{
${ }^{1}$ This is not an endorsement by the National Aeronautics and Space Administration (NASA).
} 


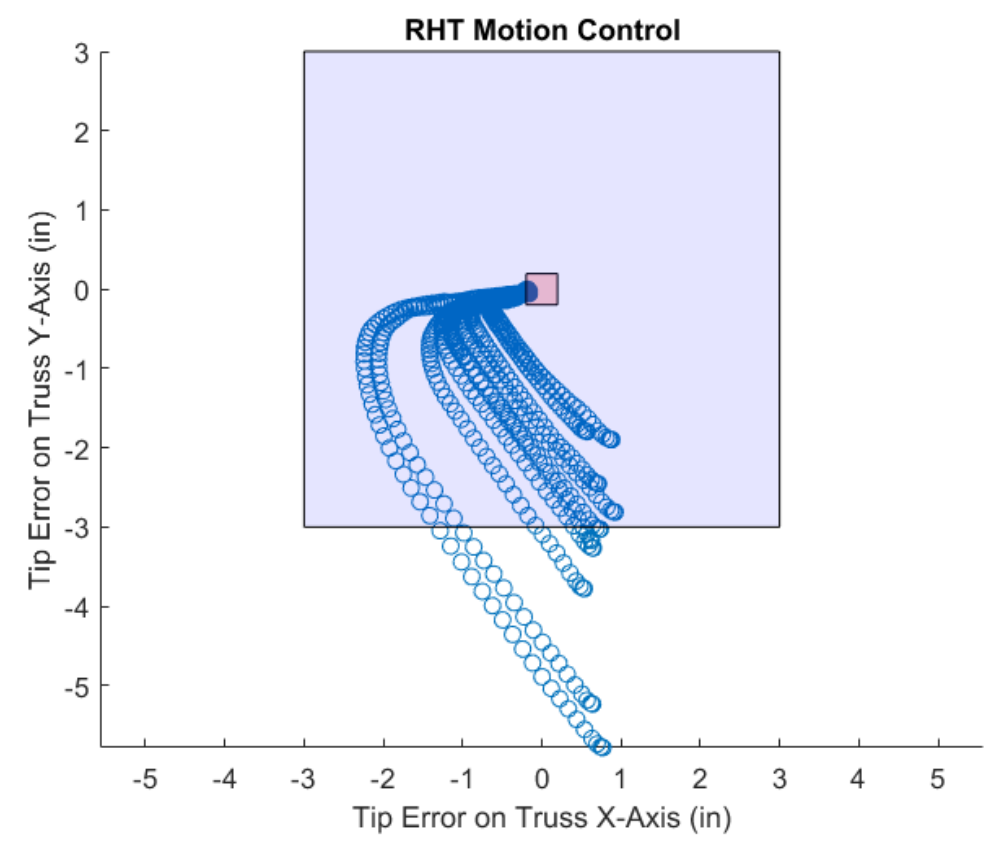

Figure 14. Close up view of RHT final wrist position in the IPJR capture box.

mockup, a set of SA modules and a turntable allowing the LSMS to access the truss from any angle. These elements are shown in Figure 15.

The backbone truss was a 4-bay square truss using the same truss hardware used in the TALISMAN assembly demonstration. Two of the ten top surface nodes were the mounting locations for the IPJR and were otherwise featureless. The eight other nodes featured a pair of $60-\mathrm{mm}$ diameter flat plates, which represented generalized assembly interfaces for the SA panels. Without requiring any other features, the plates permitted six DOF for positioning the SA modules, provided that the gap between the module legs and the plates could be filled with a joining material. In this experiment, hot melt adhesive (HMA) substituted for welding to simplify the experiment. The HMA had sufficient adherence strength to prevent the module connections from dislodging under deployment forces. However, some strain was observed at the connection, as described in a subsequent section.

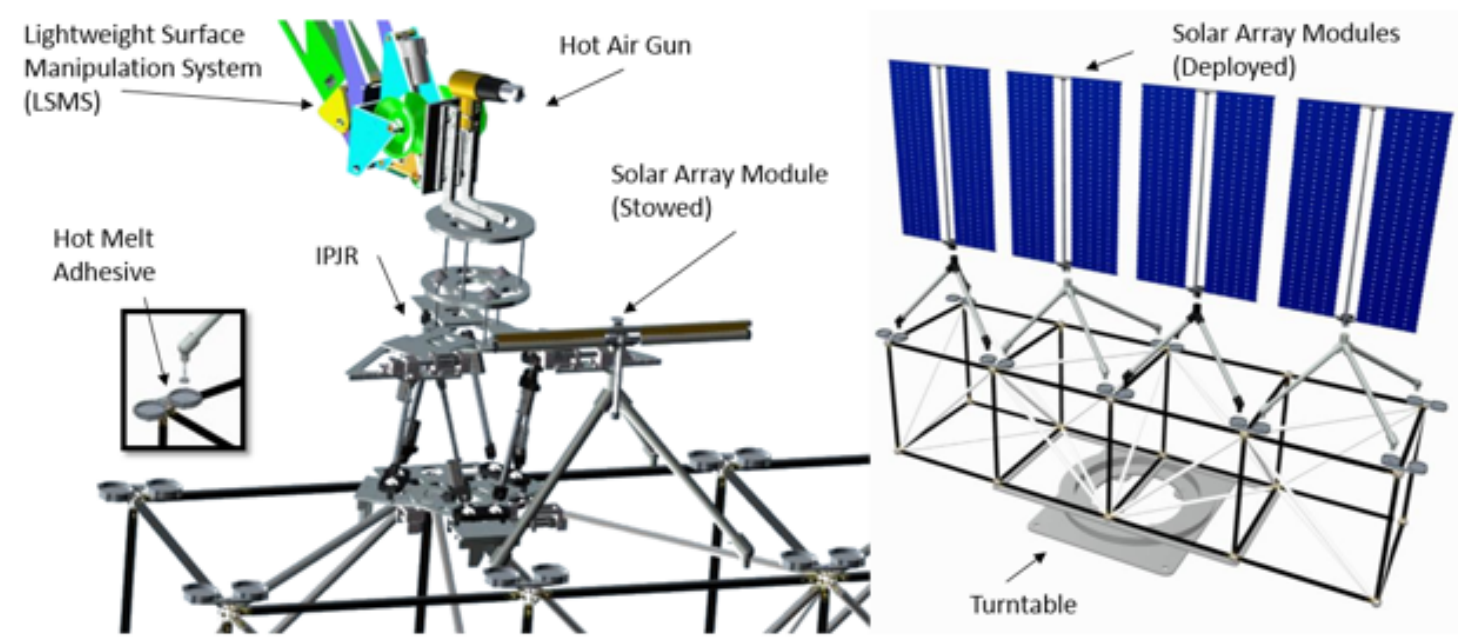

Figure 15. Diagram of relevant SA module assembly elements (left) and finished assembly (right).

Each solar panel module mockup consisted of two rolled-up plastic sheets attached by bars to a telescoping 
rod, with a tripod base for joining to the truss. Each tripod leg consisted of a threaded rod embedded in an HMA matrix, which was melted during the welding analogue step. The location for grasping the SA module by the IPJR was located at the top of the tripod base. The module could be deployed by the LSMS grappling the bar attached to the top of the telescoping rod, and pulling upward. To simulate a six DOF joint, the module legs were not allowed to come into direct contact with the truss, and were instead nominally placed $10 \mathrm{~mm}$ above the surface so that the welding analogue could fill the gap. The joints were required to withstand both the weight of the panels, and the deployment forces imparted by the LSMS.

The IPJR was responsible for grasping the truss with its bottom plate, grasping a module with its top plate, and positioning the module relative to the truss using the motion of its Stewart platform. The LSMS was, 1) used to provide mobility to the IPJR, transporting it between a solar panel storage location and the truss and, 2) perform the joining operation by using a heat gun on the HMA attached to the solar panels.

While the prototypes used in this demonstration are meant to be representative of a SEP tug assembly mission, some limitations must be noted. An ISA experiment will likely use EBW, which requires a vacuum; HMA is used in these trials as a welding analogue. Gravity affects the ground demonstrations and induces strains on the joints that will not be experienced in orbit. The LSMS is mounted to the ground, but will either be a mobile manipulator or attached to the spacecraft. All manipulators in a space mission will have onboard sensors, including computer vision and light detection and ranging (LIDAR), permitting measurement of the structure by all robots, instead of relying on a single global metrology system. Onboard sensors must also handle a stark distinction between sunlit and shaded components, which was not simulated in the laboratory. ISA will employ several joining methods besides welding, including docking with interfaces that allow power, data, and fluid transfer between components. In these trials, all robots are tethered to power supplies, but in-space robots may have their own power sources and charging stations.

\section{IV.E.2. Assembly Sequence and Results}

The complete sequence of steps that were executed during the demonstration are listed in Table 5 .

Table 5. Solar array assembly sequence.

\begin{tabular}{|l|l|l|}
\hline Step & Participants & Action \\
\hline 1 & IPJR & $\begin{array}{l}\text { The IPJR began at panel storage, a ground location } 1 \\
\text { meter away from the truss. }\end{array}$ \\
\hline 2 & IPJR, Panel & The IPJR grasped a panel module. \\
\hline 3 & IPJR, LSMS, Panel & $\begin{array}{l}\text { The IPJR grasped the LSMS which moved it to the } \\
\text { truss. This required 5-mm and 3-degree positioning } \\
\text { accuracy per axis. }\end{array}$ \\
\hline 4 & IPJR, LSMS, Truss, Panel & $\begin{array}{l}\text { The IPJR grasped the truss to the same accuracy and } \\
\text { then released the LSMS }\end{array}$ \\
\hline 5 & IPJR, Truss, Panel & $\begin{array}{l}\text { The IPJR positioned the panel module 10 mm above } \\
\text { the truss to the same accuracy. }\end{array}$ \\
\hline 6 & LSMS, Truss, Panel & $\begin{array}{l}\text { The LSMS joined legs to truss plates by filling the 10- } \\
\text { mm gaps with hot melt adhesive. }\end{array}$ \\
\hline 7 & IPJR, Panel & The IPJR released the panel. \\
\hline 8 & IPJR, LSMS, Truss & $\begin{array}{l}\text { The IPJR returned to panel storage by reversing steps } \\
\text { and } 4 .\end{array}$ \\
\hline 9 & LSMS, Panel & $\begin{array}{l}\text { The LSMS grasped one end of a telescoping rod on the } \\
\text { panel. }\end{array}$ \\
\hline 10 & LSMS, Panel & $\begin{array}{l}\text { The LSMS deployed the panel by extending the tele- } \\
\text { scoping rod. }\end{array}$ \\
\hline
\end{tabular}

The assembly sequence for an individual module was performed nine times, consisting of two complete SA assembly trials (one shown in Figure 16) and a single panel assembly trial. The primary goal of joining all modules to the truss and deploying all of their panels was successful. The IPJR successfully grasped the panels, the truss, and the LSMS without failure. The LSMS moved the IPJR, heated the HMA, and 
deployed each panel without failure. The HMA-filled gaps between the panels and the truss plates withstood the deployment forces.

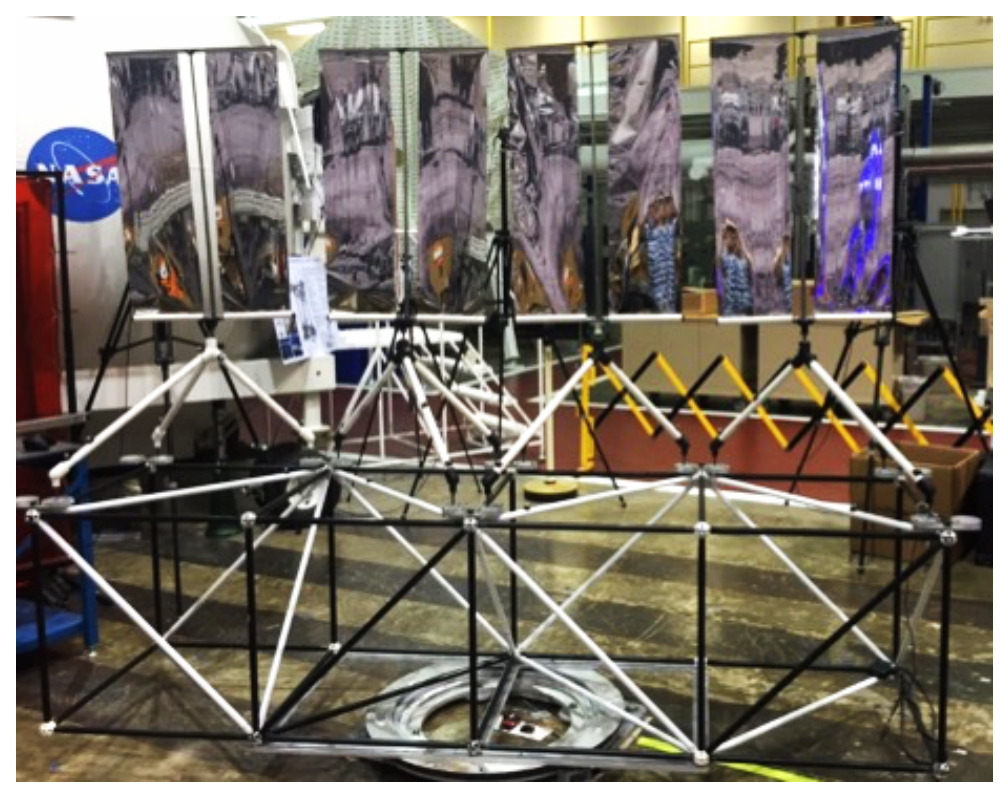

Figure 16. Completed assembly of SA.
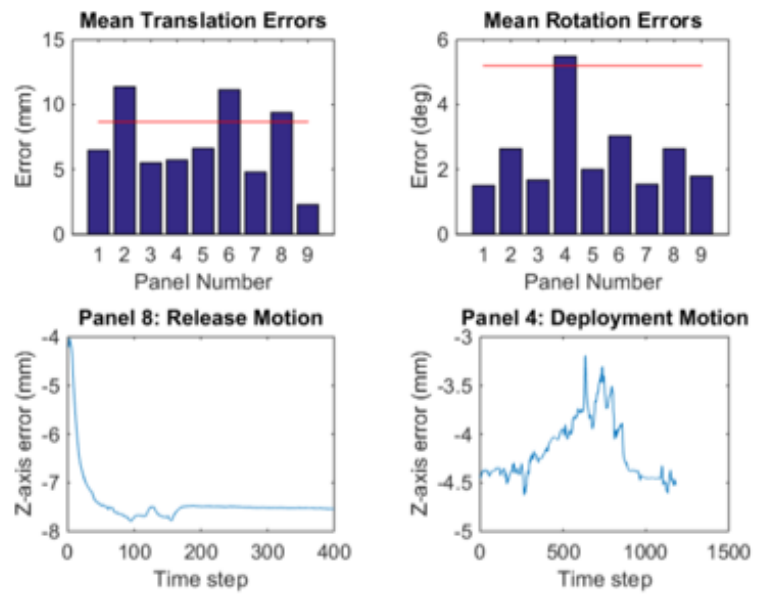

Figure 17. Top: total translation and rotation errors for the nine test panels, with acceptable errors shown as red lines. Bottom: two cases demonstrating (left) the vertical sagging of panel 8 under its own weight after being released, adding to the total error, and (right) the vertical strain placed on the joints of panel 4 by the LSMS deploying the panel.

The secondary goal was to ensure each solar panel was positioned within $5 \mathrm{~mm}$ and 3 degrees per axis, forming boxes in configuration space whose half-diagonals are $8.7 \mathrm{~mm}$ and 5.2 degrees, respectively. These errors were measured after the IPJR released the panels and were allowed to settle. The results of these are shown in the top row of Figure 17. Six of the nine panels remained within the total acceptable bounds. Three exceeded the allowable translation error, and another exceeded the allowable rotation error. Three major factors contributing to these errors were identified:

- The welding analogue was sensitive to LSMS positioning error, causing heat to be applied unevenly to the HMA. Similar errors could occur with in-space welding, which may require additional precision.

- The algorithm stopped correcting errors that entered the error boundary, placing the final pose near the acceptable boundary. This behavior is correctable. 
- The weight of the panels compressed the joints after the IPJR released the panels. This is an artifact of the gravity-based assembly process and the glue that was used.

The behavior of the latter two of these factors is illustrated in the lower left plot in Figure 17 for panel 8 ; prior to release at time step 0 , the Z-axis error was within the 5 -mm limit, but $4 \mathrm{~mm}$ below the goal. The Z-axis error then dropped to over $7 \mathrm{~mm}$ below the goal after the IPJR removed its support.

Flexibility in the glued joints was observed during the deployment phase. In addition, the friction in the telescoping rod of each panel contributed most of the resistance, with lateral forces, since the LSMS did not perfectly follow a vertical path. The panels shifted upward between $0.5 \mathrm{~mm}$ and $1 \mathrm{~mm}$ typically, then rebounded to their original position. The vertical motion of panel 4 is shown in the lower right plot of Figure 17.

\section{IV.F. Validation of SEP Tug Assembly Steps}

As stated previously, the objective of the two demonstrations was to validate the capability to perform the sequence and steps necessary to robotically assemble a large SEP tug in orbit. Table 2 has been repeated here as Table 6 with information added on which steps were validated by each test.

Between the two demonstrations, almost all of the steps required to autonomously assemble a large SEP tug in space were successfully validated for the first time.

Table 6. SEP Tug assembly steps.

\begin{tabular}{|c|c|c|c|}
\hline Step & Participants & Action & Demo. \\
\hline 1 & LBT, LHT, Connector & Attach stowed deployable LBT to spacecraft bus & No \\
\hline 2 & RBT, RHT, Connector & Attach stowed deployable RBT to spacecraft bus & No \\
\hline $3 a$ & LBT, LHT, IPJR, EBW & LHT deploys outer 2 bays of truss & Yes \\
\hline $3 \mathrm{~b}$ & & RHT positions IPJR on truss & Yes \\
\hline $3 \mathrm{c}$ & & IPJR jigs truss geometry & No \\
\hline $3 \mathrm{~d}$ & & $\begin{array}{l}\text { RHT retrieves EBW from storage and positions } \\
\text { near truss hinges/telescoping joints }\end{array}$ & No \\
\hline $3 \mathrm{e}$ & & EBW welds and inspects joints & No \\
\hline $\begin{array}{l}3 f- \\
N\end{array}$ & & $\begin{array}{l}\text { Repeat steps } 3 \mathrm{a}-3 \mathrm{e} \mathrm{N} \text { times on next two-bays } \\
\text { until truss is completely deployed and rigidized }\end{array}$ & \\
\hline $4 \mathrm{a}$ & LBT, SA, LHT, IPJR & LHT grapples IPJR & Yes \\
\hline $4 \mathrm{~b}$ & & LHT positions IPJR at SA storage location & Yes \\
\hline $4 \mathrm{c}$ & & $\begin{array}{l}\text { IPJR grapples SA module and removes it from } \\
\text { storage site }\end{array}$ & Yes \\
\hline $4 \mathrm{~d}$ & & $\begin{array}{l}\text { LHT positions IPJR/SA combination near mod- } \\
\text { ular connector on truss }\end{array}$ & Yes \\
\hline $4 \mathrm{e}$ & & IPJR installs SA onto truss modular connector & Yes \\
\hline $4 \mathrm{f}$ & & $\begin{array}{l}\text { LHT relocates IPJR tool to top of stowed SA } \\
\text { module }\end{array}$ & Yes \\
\hline $4 \mathrm{~g}$ & & $\begin{array}{l}\text { IPJR grapples deployment fixture at top of SA } \\
\text { module }\end{array}$ & Yes \\
\hline $4 \mathrm{~h}$ & & $\begin{array}{l}\text { LHT executes straight line tip motion to deploy } \\
\text { SA }\end{array}$ & Yes \\
\hline & & $\begin{array}{l}\text { Repeat steps } 4 \mathrm{a}-4 \mathrm{~h} \mathrm{~N} \text { times until all SA modules } \\
\text { have been attached to and deployed from LBT }\end{array}$ & \\
\hline $\begin{array}{l}5 \mathrm{a}- \\
\mathrm{N}\end{array}$ & RBT, RHT, IPJR, EBW & $\begin{array}{l}\text { Repeat all steps in sequence } 3 \text { to deploy and } \\
\text { rigidize the RBT. }\end{array}$ & \\
\hline $\begin{array}{l}6 \mathrm{a}- \\
\mathrm{N}\end{array}$ & RBT, SA, RHT, IPJR & $\begin{array}{l}\text { Repeat all steps in sequence } 4 \text { to attach and de- } \\
\text { ploy SA modules }\end{array}$ & \\
\hline
\end{tabular}




\section{Concluding Remarks}

The majority of spacecraft, except for the ISS, are transported to orbit as an integrated unit using a single launch. The single launch approach severely constrains the mass and size of the spacecraft system due to the mass and volume constraints of the chosen launch vehicle, as well as the loads imposed by the launch environment. Developing a robust capability for SALSSA has the potential to drastically increase the capabilities and performance of future space missions and spacecraft, while significantly reducing their cost. A large SEP tug was chosen as one potential application for the SALSSA approach and the robotic capabilities, modular discretization of tug components, and operations required to assemble the tug in orbit were developed. Due to the tug appearing in many NASA Mars exploration architectures, this application was chosen as a focus to begin advancing the technology necessary to implement ISA. This paper described crosscutting capabilities and technologies for ISA, then described and developed a detailed set of steps applicable to robotically assembling the SEP tug. Previously developed capabilities for long reach manipulation, that enable positioning of tools and manipulators used in assembly, were summarized for two manipulators. The design and development of a new class of dexterous jigging robot, the IPJR, which was used for SA jigging and assembly, was also described in detail. Two separate assembly tests were performed, and the design and development of test support hardware (trusses and SAs for example), and the setup for each test was described. In order to execute an automated assembly process, systems to control the robots (including the metrology system) were designed and developed, and are also summarized. Finally, key results of the two sets of assembly experiments were presented and compared to the assembly operations concept. The two tests successfully demonstrated and validated almost all of the steps required to autonomously assemble a large SEP tug in space. The tests also demonstrated that only a small toolbox of robotic capabilities were needed to accomplish all of the assembly steps if the capabilities are versatile. The required operational versatility was successfully demonstrated during the tests. More importantly, the LaRC tests proved that modular spacecraft design, in conjunction with ISA, was completely viable, and validated that the approach is ready to be baselined for implementation in subsequent future mission architectures and spacecraft designs.

\section{References}

\footnotetext{
${ }^{1}$ Dorsey, J. and Watson, J., "Space Assembly of Large Structural System Architectures (SALSSA)," AIAA SPACE 2016 , 2016, p. 5481.

${ }^{2}$ Craig, D. A., Herrmann, N. B., and Troutman, P. A., "The Evolvable Mars Campaign-Study Status," Aerospace Conference, 2015 IEEE, IEEE, 2015, pp. 1-14.

${ }^{3}$ Bobskill, M. R., Lupisella, M. L., Mueller, R. P., Sibille, L., Vangen, S., and Williams-Byrd, J., "Preparing for Mars: Evolvable Mars Campaign Proving Ground approach," Aerospace Conference, 2015 IEEE, IEEE, 2015, pp. 1-19.

${ }^{4}$ Committee for a Decadal Survey of Astronomy and Astrophysics; National Research Council, "New Worlds, New Horizons in Astronomy and Astrophysics," 2010.

${ }^{5}$ Kouveliotou, C., Agol, E., Batalha, N., Bean, J., Bentz, M., Cornish, N., Dressler, A., Figueroa-Feliciano, E., Gaudi, S., Guyon, O., et al., "Enduring Quests-Daring Visions (NASA Astrophysics in the Next Three Decades)," arXiv:1401.3741, 2014.

${ }^{6}$ NASA, "Draft 2015 NASA Technology Roadmaps," http://http://www.nasa.gov/offices/oct/home/roadmaps/index. html, Accessed: 2016-07-20.

${ }^{7}$ Belvin, W. K., Doggett, W. R., Watson, J. J., Dorsey, J. T., Warren, J., Jones, T. C., Komendera, E. E., Mann, T., and Bowman, L., "In-Space Structural Assembly: Applications and Technology," 3rd AIAA Spacecraft Structures Conference, 2016, p. 2163.

${ }^{8}$ Mercer, C. R., McGuire, M. L., Oleson, S. R., and Barrett, M. J., Solar Electric Propulsion Concepts for Human Space Exploration, NASA/TM-2016-218921, 2016.

${ }^{9}$ Feinberg, L. D., Budinoff, J., MacEwen, H., Matthews, G., and Postman, M., "Modular Assembled Space Telescope," Optical Engineering, Vol. 52, No. 9, 2013, pp. 091802-091802.

${ }^{10}$ Jefferies, S. A., McCleskey, C. M., Nufer, B., Lepsch, R. A., Merrill, R. G., North, D., Martin, J., and Komar, D. R., "Viability of a Reusable In-Space Transportation System," Proceedings of the AIAA SPACE 2015 Conference and Exposition, SPACE Conferences and Exposition, Pasadena, California; http://dx. doi. org/10.2514/6.2015-4580, 2015.

${ }^{11}$ Doggett, W. R., King, B. D., Jones, T. C., Dorsey, J. T., and Mikulas, M. M., "Design and Field Test of a Mass Efficient Crane For Lunar Payload Handling and Inspection-The Lunar Surface Manipulation System," AIAA Space 2008 Conference and Exposition, 2008, pp. 9-11.

${ }^{12}$ Doggett, W. R., King, B. D., Collins, T. J., and Dorsey, J. T., "Robotic-Movement Payload Lifter and Manipulator," Feb. 1 2011, US Patent 7,878,348.

${ }^{13}$ Doggett, W. R., Dorsey, J. T., Ganoe, G. G., King, B. D., Jones, T. C., Mercer, C. D., and Corbin, C. K., "Tension Stiffened and Tendon Actuated Manipulator," Oct. 27 2015, US Patent 9,168,659.

${ }^{14}$ Doggett, W. R., Dorsey, J., and Jones, T. C., "Improvements to the Tendon-Actuated Lightweight In-Space MANipulator (TALISMAN) System," AIAA SPACE 2015 Conference and Exposition, 2015, p. 4682.
} 
${ }^{15}$ Komendera, E. E., Doggett, W. R., Dorsey, J. T., Debus, T. J., Holub, K., and Dougherty, S. P., "Control System Design Implementation and Preliminary Demonstration for a Tendon-Actuated Lightweight In-Space MANipulator (TALISMAN)," Proceedings of the AIAA SPACE Conference, 2015.

${ }^{16}$ Komendera, E. E., Adhikari, S., Glassner, S., Kishen, A., and Quartaro, A., "Structure Assembly by a Heterogeneous Team of Robots Using State Estimation, Generalized Joints, and Mobile Parallel Manipulators," Proceedings of the IEEE/RSJ International Conference on Intelligent Robots and Systems, 2017.

${ }^{17}$ Mikulas, M., Pappa, R., Warren, J., and Rose, G., "Telescoping Solar Array Concept for Achieving High Packaging Efficiency," AIAA Spacecraft Structures Conference, 2015.

${ }^{18}$ Doggett, W. R., Dorsey, J. T., Jones, T. C., and King, B., "Development of a Tendon-Actuated Lightweight In-Space MANipulator (TALISMAN)," Proceedings of the 42nd Aerospace Mechanisms Symposium, Vol. 405, 2014.

${ }^{19}$ Komendera, E. E., Dorsey, J. T., Doggett, W. R., and Correll, N., "Truss Assembly and Welding by Intelligent Precision Jigging Robots," Proceedings of the 6th Annual IEEE Int. Conf. on Technologies for Practical Robot Applications (TEPRA), 2014.

${ }^{20}$ Komendera, E. and Correll, N., "Precise Assembly of 3D Truss Structures using MLE-Based Error Prediction and Correction," The International Journal of Robotics Research, Vol. 34, No. 13, 2015, pp. 1622-1644.

${ }^{21}$ Actuonix, "P16 Series Mini Linear Actuators," https://www. actuonix.com/P16-Actuators-s/1861.htm, Accessed: $2017-$ 08-13.

${ }^{22}$ Arduino, "Arduino - Home," https://www.arduino.cc, Accessed: 2017-08-13.

${ }^{23}$ Vicon, "Motion Capture Systems - Vicon," http://www.vicon.com, Accessed: 2016-07-20.

${ }^{24}$ Ljung, L., "Asymptotic Behavior of the Extended Kalman Filter as a Parameter Estimator for Linear Systems," IEEE Transactions on Automatic Control, Vol. 24, No. 1, 1979, pp. 36-50. 